\title{
Detection of biological objects using dynamic characteristics of double-walled carbon nanotubes
}

\author{
Ajay M. Patel $\cdot$ Anand Y. Joshi
}

Received: 23 July 2014/Accepted: 23 September 2014/Published online: 9 October 2014

(C) The Author(s) 2014. This article is published with open access at Springerlink.com

\begin{abstract}
This study explores double-walled carbon nanotubes as the sensing devices for biological objects including viruses and bacteria. The biological objects studied include alanine with amino terminal residue, deoxyadenosine with free residue, Coronaviridae and Bartonella bacilliformis. An expression has been articulated to identify the mass of biological objects from the shift of frequency. Sensitivity of the sensor has been calculated when subjected to such biological objects. Molecular structural mechanics approach has been used for investigating the vibrational responses of zigzag and armchair double-walled carbon nanotube-based nano biosensors. The elastic properties of beam element are calculated by considering mechanical characteristics of covalent bonds between the carbon atoms in the hexagonal lattice. Spring elements are used to describe the interlayer interactions between the inner and outer tubes caused due to the van der Waals forces. The mass of each beam element is assumed as point mass at nodes coinciding with carbon atoms at inner and outer wall of DWCNT. Based on the sensitivity and the frequency shift it can be concluded that cantilever zigzag DWCNTs are better candidates for detecting the biological objects.
\end{abstract}

Keywords DWCNT - Biosensor · Coronaviridae · Bartonella bacilliformis $\cdot$ Sensitivity

\footnotetext{
A. M. Patel

Mechanical Engineering Department, CHARUSAT University, Changa, Gujarat, India

e-mail: ajaympatel2003@yahoo.com
}

\section{A. Y. Joshi $(\bowtie)$}

Mechatronics Engineering Department, G.H. Patel College of Engineering \& Technology, Vallabh Vidyanagar, Gujarat, India e-mail: anandyjoshi@gmail.com

\section{Introduction}

In recent times there has been a fast growing interest of CNTs in biological applications (Tsang et al. 1995; Davis et al. 1998; Wong et al. 1998; Mattson et al. 2000) in the field of medicine (Lu et al. 2009) and sensing mechanisms (Lin et al. 2004; Gu et al. 2005) specifically as biosensors. The application of CNTs has been explored for the development of electro analytical nanotube devices (Mattson et al. 2000), ultrasensitive nano-bio sensors (Wong et al. 1998; Baughman et al. 1999) and electromechanical actuators for artificial muscles (Davis et al. 2003). Since the discovery of carbon nanotubes (CNTs) (Iijima 1991; Iijima and Ichihashi 1993) in 1991 they have emerged as a new class of nanomaterials (Dresselhaus et al. 2001; Haddon 2002). Due to their unique physical properties (Lin et al. 2004; Gu et al. 2005; Ajayan 1999; Ajayan et al. 1999), they have been used in a variety of applications in fields such as scanning probes (Wang 2005; Kumar et al. 2008; Yun et al. 2007), nano electronics, storage devices (Rivas et al. 2007; Fennimore et al. 2003) and nano electromechanical systems.

The growth of nano-bio sensors (Lee and Yoon 2007) and nanoscale bioreactor systems based on CNTs has been driven by the experimental indication that biological entities such as proteins, enzymes and bacteria can be immobilized either in the hollow cavity or on the surface of carbon nanotubes (Tsang et al. 1995; Davis et al. 1998). Significant efforts are being made for the use of CNTs as superior biosensor materials, in the light of successful fabrication of various electro analytical nanotube devices, modified by external biological agents (Davis et al. 2003; Chen et al. 2003; Gooding et al. 2003; Li et al. 2003). These devices, prepared as single-walled carbon nanotube (SWCNT) transistors, have shown promising sensitivities 
required for such applications as antigen recognition (Chen et al. 2003) and DNA hybridizations ( $\mathrm{Li}$ et al. 2003).

It has been observed that viruses like Coronaviridae contain a wide range of major pathogens that affect mammals and birds causing a variety of disease conditions including: respiratory disease (human, chicken and rats), gastro-enteritis (cattle, horses, pigs, dogs, turkey and mice), encephalomyelitis (pigs and mice), hepatitis (mice), myocarditis (rabbits), peritonitis (cats) and nephritis (chicken). In humans, coronaviruses are part of the spectrum of viruses that cause the common cold (Amer and Almajhdi 2011).

Also, Bartonella bacilliformis is the etiologic agent of Carrion's disease or Oroya fever (acute phase of infection) and Verruga peruana or Peruvian wart (chronic phase of infection). The acute phase of the disease is life threatening, characterized by massive invasion of bartonella to human red blood cells and consequently an acute hemolysis and fever (Maguina and Gotuzzo 2000). Bartonella, the agent of trench fever and a cause of endocarditis and bacillary angiomatosis in humans, has been highest reported in vitro hemin requirement for any bacterium (Carroll et al. 2000). Hence, it is very important to safeguard against these viruses by sensing the presence and amount of the same. As CNTs possess a very high sensitivity in terms of mass sensing characteristics, doublewalled carbon nanotubes are used in this manuscript for sensing the presence of these biological objects. The biological objects and their corresponding mass values have been shown in Table 1.

Two common methods are used for discovering the mechanical behavior of nanostructures, namely continuum mechanics and atomistic-based modeling approaches. Molecular dynamics (MD) is an accurate method capable of simulating the full mechanical DWCNT performance. The free vibrations of CNTs have been investigated by Sohlberg et al. (1998). Applying the interactions at the atomic scale it is found that atomistic approaches are more reliable than continuum based methods ( $\mathrm{Li}$ and Chou 2004; Sanchez-Portal et al. 1999; Dereli and Ozdogan 2003). Blevins used the Euler-Bernoulli beam theory to derive corresponding eigenvalues of the CNT vibration (Blevins 1979). Yoon et al. (2003) studied the resonant frequency and associated vibrational modes of an individual multiwalled carbon nanotube (MWCNTs) embedded in elastic medium. Xu et al. (2008) researched the free vibrations of DWCNT modeled as elastic beams due to different boundary conditions between inner and outer tubes. $\mathrm{Li}$ and Chou (2003) developed an equivalent structural beam to mimic interatomic forces of the covalently bonded carbon atoms. Later, Tserpes and Papanikos (2005) presented the atomistic finite element (FE) model of single-walled
Table 1 List of biological objects and its corresponding mass values

\begin{tabular}{lll}
\hline $\begin{array}{l}\text { Sr } \\
\text { no }\end{array}$ & Name & Mass $M_{i}(\mathrm{~g})$ \\
\hline 1 & $\begin{array}{c}\text { Alanine with } \\
\text { amino terminal } \\
\text { residue }\end{array}$ & $1.21307 \times 10^{-22} \leq M_{i} \leq 9.70456 \times 10^{-22}$ \\
2 & $\begin{array}{c}\text { Deoxyadeonosine } \\
\text { with free residue }\end{array}$ & $4.16965 \times 10^{-22} \leq M_{i} \leq 2.918755 \times 10^{-21}$ \\
3 & $\begin{array}{c}\text { Coronaviridae } \\
4\end{array}$ & $\begin{array}{c}\text { Bartonella } \\
\text { bacilliformis }\end{array}$ \\
\hline
\end{tabular}

carbon nanotubes (SWCNTs) based on the Li and Chou equivalent structural beam concept.

Patel and Joshi (2013) analyzed vibrational characteristics of double-walled carbon nanotube modeled using spring elements and lumped masses. The inner and outer walls of carbon nanotube were modeled as two individual elastic beams connecting each other by van der Waals forces. Also it has been reported that SWCNT-based sensors exhibit super-harmonic and sub-harmonic response with different level of mass (Joshi et al. 2010). Periodic and different nonlinear behavior of SWCNT is exposed as mass is attached at different positions along the length (Joshi et al. 2010). Patel and Joshi (2014) have also investigated resonant frequency of double-walled carbon nanotubes with deviations along it is axis and different boundary conditions, namely cantilever and bridged. The sensitivity of the apparently deviated double-walled carbon nanotubes, different masses attached to the end of outer tube tip and center of the outer tube of the bridged DWCNT and different lengths have been explored and presented. The effect of waviness along the axis has been evaluated by subjecting the nanotube to different boundary conditions, namely bridged, cantilever and simply supported and the vibration responses of straight and wavy DWCNTs are investigated by Patel and Joshi (2014). Jensen et al. (2008) have demonstrated a room temperature, carbon-nanotubebased nano mechanical resonator with atomic mass resolution. It is surely a mass spectrometer with a mass sensitivity of $1.3 \times 10^{-25} \mathrm{~kg} \mathrm{~Hz}^{-1 / 2}$ or, equivalently, 0.40 gold atoms $\mathrm{Hz}^{-1 / 2}$. The mass sensing capabilities of multiwalled CNTs have been investigated by Georgantzinos and Anifantis (2010).

In the current study, the authors have evaluated the potential of using DWCNTs as nanomechanical resonators for sensing mass of biological objects which include Alanine with Amino terminal residue, Deoxyadenosine with free residue, Coronaviridae and Bartonella bacilliformis. 


\section{Atomic structure of double-walled carbon nanotube}

A double-walled carbon nanotube consists of two layers of graphite rolled to form a tube. In other words, a DWCNT consists of two coaxial layers, where the interlayer distance is close to the distance between graphene layers in graphite, approximately $0.34 \mathrm{~nm}$.

As shown in Fig. 1, CNTs are categorized as tubes formed by rolling a sheet of graphene about the $\vec{T}$ vector. A vector perpendicular to the $\vec{T}$ is the chiral vector denoted by $\vec{C}_{\mathrm{h}}$. The chiral vector and the corresponding chiral angle define the type of CNT, i.e. zigzag, armchair, chiral. $\vec{C}_{\mathrm{h}}$ can be expressed with respect to two base vectors $\overrightarrow{a_{1}}$ and $\overrightarrow{a_{1}}$ as under

The chiral vector $C_{\mathrm{h}}$ of the nanotube is shown in Fig. 1, defined by

$\overrightarrow{C_{\mathrm{h}}}=n \overrightarrow{a_{1}}+m \overrightarrow{a_{2}}$

where $\overrightarrow{a_{1}}$ and $\overrightarrow{a_{2}}$ are unit vectors in the two-dimensional hexagonal lattice, and $\mathrm{n}$ and $\mathrm{m}$ are integers. If the indices of translation are such that $m=0$ and $n=m$ then the corresponding CNTs are categorized as zigzag and armchair, respectively.

The outer diameter $D_{\mathrm{o}}$ of DWCNT can be calculated from the diameter of the corresponding outer $(n, m)$ SWCNT as given by the following equation:

$D_{\mathrm{o}}=\frac{1}{\pi} a_{\mathrm{c}-\mathrm{c}} \sqrt{3\left(n^{2}+n m+m^{2}\right)}$,

where $a_{\mathrm{c}-\mathrm{c}}$ is the distance between two neighboring carbon atoms equal to $0.1421 \mathrm{~nm}$.

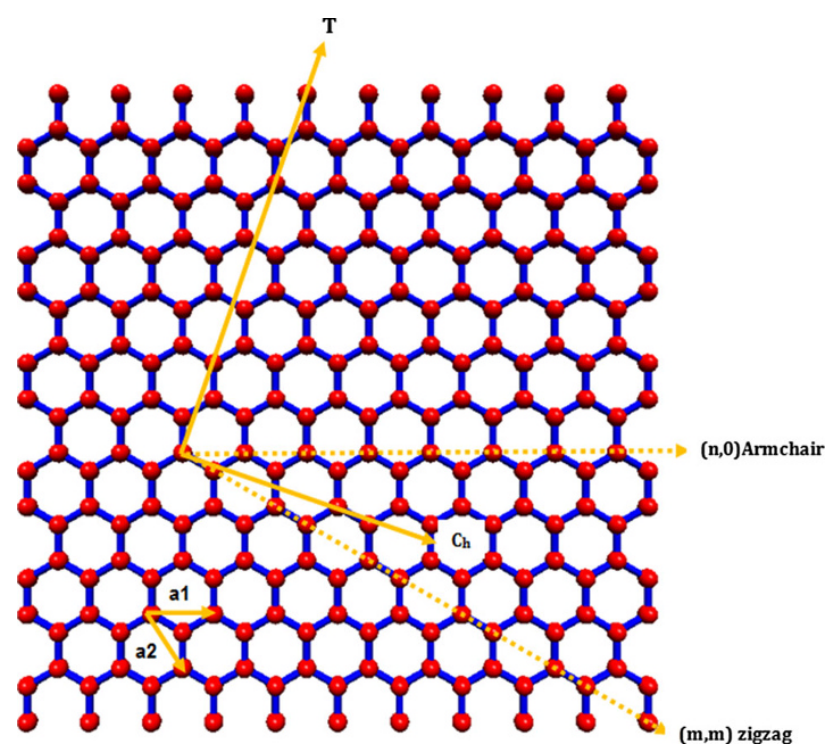

Fig. 1 Hexagonal lattice of graphene sheet including base vectors

\section{Atomic finite element modeling of dwcnt}

A finite element model made of beam elements and a concentrated mass are employed and the vibrational characteristics of cantilever and bridged DWCNT with different type of biological objects are explored. The elastic properties of the beam elements are calculated to consider the interatomic covalent forces between carbon atoms. The concentrated masses which represent the mass of the carbon atom are placed at the end of the beams, which represent covalent bond between the carbon atoms. The schematic diagram of armchair DWCNT $(10,10) @(5,5)$ and zigzag DWCNT $(14,0) @(10,0)$ with the beam elements and point masses are shown in Fig. 2a, b, respectively.

In this paper, for utilizing the finite element procedure, potential energy is used to evaluate linear nanospring stiffness. The total force on each atomic nuclei is the sum of the force generated by the electrons and electrostatics force between the positively charged nuclei themselves. The general formula for the potential energy is

$\pi=\sum Q_{\mathrm{r}}+\sum Q_{\theta}+\sum Q_{\phi}+\sum Q_{\omega}+\sum Q_{\mathrm{vdw}}$,

where $Q_{\mathrm{r}}$ is the energy due to bond stretch interaction, $Q_{\theta}$ the energy due to bending (bond angle variation), $Q_{\phi}$ the energy due to dihedral angle torsion, $Q_{\omega}$ the energy due to out-of-plane torsion and $Q_{\mathrm{vdw}}$ the energy due to nonbonded Vander Waals interaction.

$Q_{\mathrm{r}}=\frac{1}{2} K_{\mathrm{r}}\left(r-r_{0}\right)^{2}=\frac{1}{2} K_{\mathrm{r}}(\Delta r)^{2}$

$Q_{\theta}=\frac{1}{2} K_{\theta}\left(\theta-\theta_{0}\right)^{2}=\frac{1}{2} K_{\theta}(\Delta \theta)^{2}$

$Q_{\tau}=Q_{\phi}+Q_{\omega}=\frac{1}{2} K_{\tau}(\Delta \phi)^{2}$,

where $K_{\mathrm{r}}, K_{\theta}$ and $K_{\tau}$ are the bond stretching, bond bending and torsional resistance force constants, respectively, while $\Delta r, \Delta \theta$ and $\Delta \phi$ represent bond stretching increment, bond angle variation and angle variation of bond twisting, respectively. In contrast to the other bonded interactions, the van der Waals interactions and the electrostatic forces may be neglected due their minor effects in terms of predicting the dynamic response of CNTs.

As the potential energy in the two approaches is independent, energy equivalence of the stored energy of the two approaches, i.e. molecular mechanics and structural mechanics leads to ( $\mathrm{Li}$ and Chou 2003)

$\frac{\mathrm{EA}}{L}=K_{\mathrm{r}} \quad \frac{\mathrm{EI}}{L}=K_{\theta}, \quad \frac{\mathrm{GJ}}{L}=K_{\tau}$.

The elastic properties of the beam element are given as (Li and Chou 2003) 
Fig. 2 a, b Atomic finite element model of $(10$, $10) @(5,5)$ zigzag and $(14,0) @(10,0)$ armchair DWCNT with beam elements and point masses
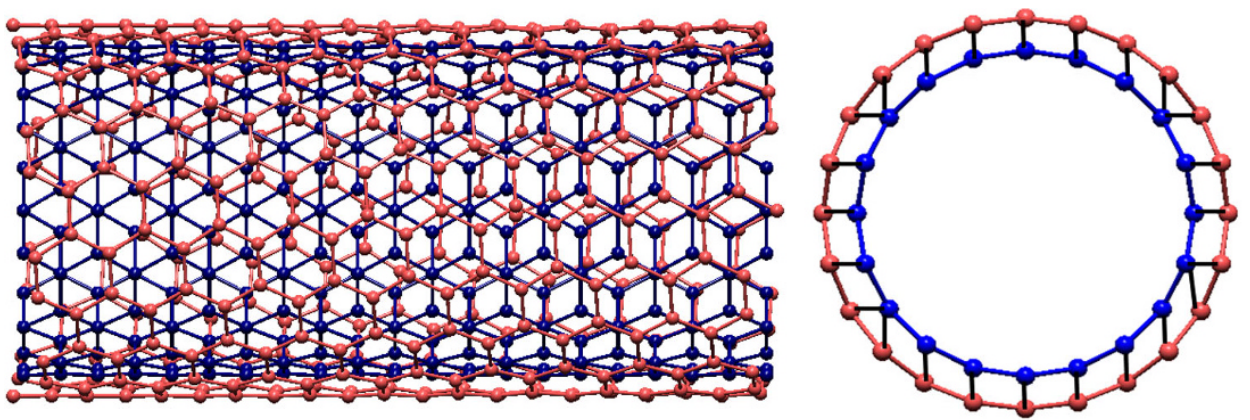

(a) $(10,10) @(5,5)$ zigzag DWCNT
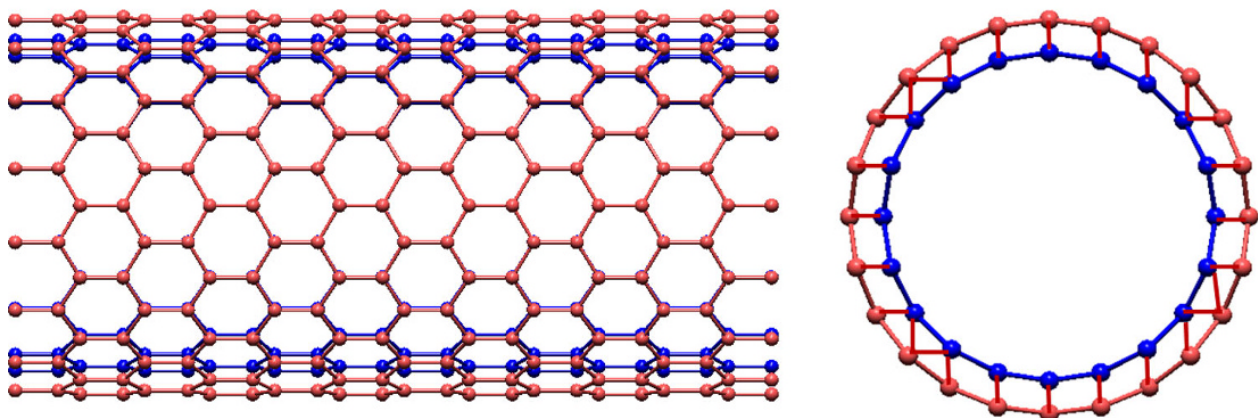

(b) $(14,0) @(10,0)$ armchair DWCNT

$d=\sqrt{\frac{K_{\theta}}{K_{\mathrm{r}}}}, \quad E=\frac{K_{\mathrm{r}}^{2} L}{4 \pi K_{\theta}}, \quad G=\frac{K_{\mathrm{r}}^{2} K_{\tau}^{L}}{8 \pi K_{\theta}^{2}}$,

where $d, L, E$ and $G$ represent the diameter, length, Young's modulus and shear modulus of the beam element.

The second derivatives of the potential energy terms in Eqs. (4)-(6) with respect to bond length, bond angle and twisting bond angle variations produce the spring stiffness coefficients $k_{\mathrm{r}}, k_{\theta}$ and $k \tau$ according to Castigliano's theorem. The angle bending interaction is simulated with an axial nanospring, using the simplification described in (Giannopoulos et al 2008). The stiffness $K_{\mathrm{s}}$ of special spring is defined by following equation:

$K_{\mathrm{s}}=\left(\frac{1}{a_{\mathrm{c}-\mathrm{c}} \cos (60)^{0}}\right)^{2} K_{\theta}$.

The angle may be varying for each $\mathrm{C}-\mathrm{C}-\mathrm{C}$ microstructure in a CNT according to its type and radius, due to cylindrical shape. Figure 3 Shows a DWCNT of the outer tube radius $R_{2}$, inner tube radius $R_{1}$ with spring element used to represent the week Van der Waals (vdW) force and atomic mass at node, using the Leonard-Jones model. The van der Waals force field between the interfacial layers is represented by a spring element COMBIN14. The spring stiffness coefficient of Eqs. (4)(6) is taken to be equal to $K_{\mathrm{r}}=6.52 \times 10^{-7} \mathrm{~N} \mathrm{~nm}^{-1}$, $K_{\theta}=8.76 \times 10^{-10} \mathrm{~N} \mathrm{~nm} \mathrm{rad}{ }^{-2}$ and $K_{\tau}=2.78 \times 10^{-10}$ $\mathrm{N} \mathrm{nm} \mathrm{rad}{ }^{-2}$ (Cornell et al. 1995). In order to simulate the

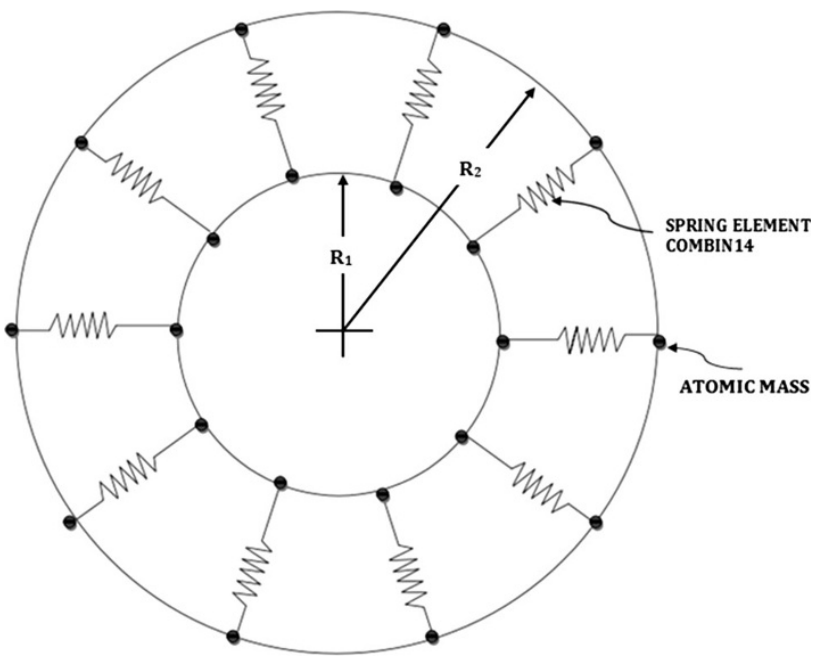

Fig. 3 DWCNT of the outer tube radius $R_{2}$, inner tube radius $R_{1}$ with spring element COMBIN14 and atomic mass at node

inertia effects, a point mass equal to a whole or half of the carbon atomic nucleus mass $\left(M=1.9943 \times 10^{-26} \mathrm{~g}\right)$ is added to a node in a particular elements. For simulating the structure, a structural point mass is added on all nodes as element.

The interlayer interaction is described by the van der Waals potential. The Lenard-Jones $6-12$ potential is utilized to express the interaction of carbon atoms located on the different walls 
$Q(R)=4 \varepsilon\left[\left(\frac{\rho}{R}\right)^{12}-\left(\frac{\rho}{R}\right)^{6}\right]$

where $R$ is the interatomic distance and $\varepsilon=3.8655 \times$ $10^{-13} \mathrm{~N}$ nm and $\sigma=0.34 \mathrm{~nm}$, respectively ( $\mathrm{Li}$ and Chou 2004). Let $R_{1}$ be the initial distance between two carbon atoms located in different walls. A nanospring with initial length $R_{1}$ is considered to describe the van der waals interaction. Consistent with the stiffness definition of the suggested nanospring, $K_{\mathrm{vdw}}$ is described as the stiffness coefficient, acquired from the second derivative of the van der Waal potential energy for distance $R_{1}$ as follows:

$K_{\mathrm{vdw}}=\frac{\mathrm{d} Q\left(R_{1}\right)}{\mathrm{d} R_{1}}=24 \frac{\varepsilon}{\sigma}\left[2\left(\frac{\sigma}{R_{1}}\right)^{13}-\left(\frac{\sigma}{R_{1}}\right)^{7}\right]$

For $R_{1}$ is the interatomic distance.

\section{Vibration analysis of DWCNT for sensing biological objects}

In DWCNTs with the inner tube length $L_{1}$ and outer tube length $L_{2}$, the interaction between the inner and outer nanotubes is considered to be coupled together through the van der Waals (vdW) forces. The interaction pressure at any point between any two adjacent tubes is a linear function and is the difference of their deflection at that point. By Euler-Bernoulli beam theory, the differential equations controlling the motion for DWCNTs are described by two-coupled differential equations:

$\rho A_{1} \frac{\partial^{2} u_{1}(x, t)}{\partial t^{2}}+\mathrm{EI} \frac{\partial^{4} u_{1}(x, t)}{\partial x^{4}}=c\left(u_{2}(x, t)-u_{1}(x, t)\right)$

$\rho A_{2} \frac{\partial^{2} u_{2}(x, t)}{\partial t^{2}}+\mathrm{EI}_{2} \frac{\partial^{4} u_{2}(x, t)}{\partial x^{4}}=-c\left(u_{2}(x, t)-u_{1}(x, t)\right)$,

where the subscripts 1 and 2 define the quantities associated with the inner and outer nanotubes, respectively. $u_{i}(x, t) \quad(i=1,2)$ are the transverse deflection of the inner and outer nanotubes, respectively. C stands for the Van der Waals interaction coefficient between nanotubes, which can be obtained from the interlayer energy potential and given as (He et al. 2005)

$c=\frac{\Pi_{\varepsilon} R_{1} R_{2} \sigma^{6}}{a^{4}}\left[\frac{1001 \sigma^{6}}{3} H^{13}-\frac{1120}{9} H^{7}\right]$,

where
$H^{m}=\left(R_{1}+R_{2}\right)^{-m} \int_{0}^{\Pi / 2} \frac{\mathrm{d} \theta}{\left(1-K \cos ^{2} \theta\right)^{m / 2}},(m=7,13)$

$K=\frac{4 R_{1} R_{2}}{\left(R_{1}+R_{2}\right)^{2}}$

where $R_{1}$ and $R_{2}$ are the inner radius and outer radius of the DWCNT.

$c=\frac{320 \times 2 R_{1}}{0.16 a^{2}}$,

where $c=6.943 \times 10^{11} \mathrm{erg} / \mathrm{cm}^{3}=69.43 \mathrm{GPa}$, where $a=0.142 \mathrm{~nm}$ is the carbon-carbon bond length and $\sigma$ and $\varepsilon$ are the vdW radius and the well depth of the LennardJones potential, respectively. The vdW parameters in the Lennard-Jones potential are $\varepsilon=2.967 \mathrm{meV}$ and $\sigma=0.34 \mathrm{~nm}$ as reported by Saito et al. (2001).

For a DWCNT of inner tube and outer tube length are equal $L_{1,2}=L$ with attached mass, based on the fundamental resonance frequency can be expressed as

$f_{n}=\frac{1}{2 \pi} \sqrt{\frac{k_{\mathrm{eq}}}{m_{\mathrm{eq}}}}$

where, $k_{\mathrm{eq}}$ and $m_{\mathrm{eq}}$ are equivalent stiffness and mass of DWNCT with attached mass in the first mode of vibration, respectively.

Cantilever DWCNT with a mass at the tip

The resonant frequency of vibration for DWCNT was calculated by the well-known vibration equation:

$f_{n}=\frac{\xi_{n}^{2}}{L^{2}} \sqrt{\frac{E\left(I_{1}+I_{2}\right)}{\rho\left(A_{1}+A_{2}\right)}}$,

where $E$ the Young's modulus, $I_{1,2}$ the second moment of the cross-sectional area $A_{1}, 2$, and $\rho$ is the density of DWCNTs. The values $\xi_{n}(n=1,2, \ldots)$ of the cantilevered beam can be found by solving the equation, $\cos \xi \cosh \xi+$ $1=0, \xi_{1}=1.875, \xi_{2}=4.694$ and $\xi_{3}=7.854$ for the first, second and third modes, respectively. $\xi_{n}=(n+0.5) \pi$ for the larger mode $n$.

Figure 4 shows that cantilevered DWCNT resonator of length $L$ with an attached biomass Alanine with amino terminal residue with a of $1.213071 \mathrm{E}^{-22} \mathrm{~g}$ mass at the end of tip.

The vibration mode can be expressed as cantilever DWCNT 
Fig. 4 Cantilevered DWCNT resonator of length $L$ with an attached biomass Alanine with amino terminal residue at the end of tip

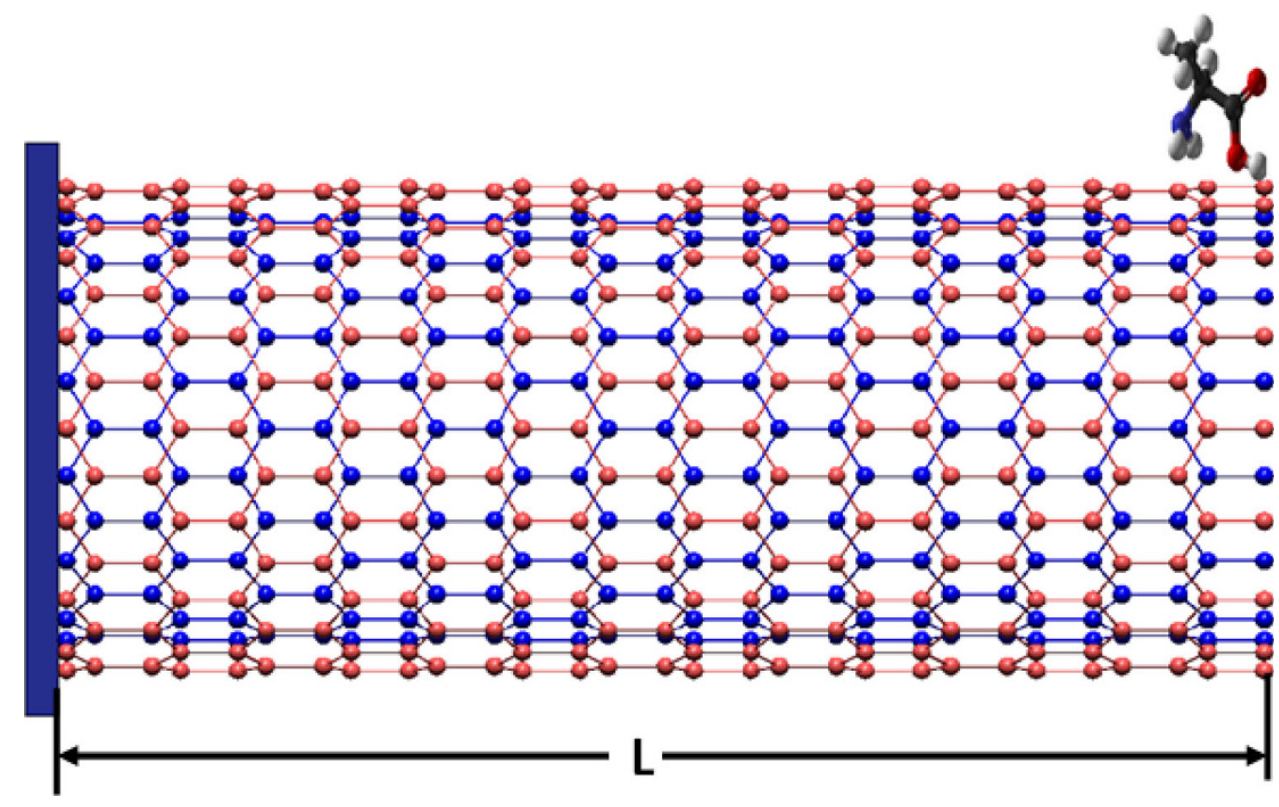

$$
\begin{aligned}
U_{n}(x)= & \left(\cosh \xi_{n} \frac{x}{L}-\cos \xi_{n} \frac{x}{L}\right)-\left(\frac{\sinh \xi_{n}-\sin \xi_{n}}{\cosh \xi_{n}+\cos \xi_{n}}\right) \\
& \times\left(\sinh \xi_{n} \frac{x}{L}-\sin \xi_{n} \frac{x}{L}\right)
\end{aligned}
$$

The mode shape in Eq. (20) is normalized such that

$\frac{1}{L} \int_{0}^{L} U_{n}^{2}(x) \mathrm{d} x=1$

The equivalence between the actual mass loaded DWCNT and the virtual single-DOF(SDOF) oscillator can be established be equating the potential and kinetic energies of both the systems. One needs to consider a deflection shape for the DWCNT. Since the cantilevered DWCNT is vibrating in the first mode, it is natural to consider the deflection proportional to the first mode of vibration given by (20) with $\xi=1.8751$. This value is obtained (Meirovitch 1997) by solving the transcendental equation $\cos \xi \cosh \xi+1=0$. Therefore, the assumed deflection is

$U(x)=a U_{1,2}(x)$,

where $\alpha$ is constant amplitude.

The potential energy of the outer walled DWCNT can be obtained as

$P_{1}=\frac{1}{2} \mathrm{EI}_{1} \int_{0}^{L}\left[\frac{\partial^{2} U_{1}(x)}{\partial x^{2}}\right]^{2} \mathrm{~d} x=\frac{1}{2} \mathrm{EI}_{1} \alpha^{2} \int_{0}^{L}\left[\frac{\partial^{2} U_{1}(x)}{\partial x^{2}}\right]^{2} \mathrm{~d} x$.

The potential energy of the inner walled DWCNT can be obtained as
$P_{2}=\frac{1}{2} \mathrm{EI}_{2} \int_{0}^{L}\left[\frac{\partial^{2} U_{2}(x)}{\partial x^{2}}\right]^{2} \mathrm{~d} x=\frac{1}{2} \mathrm{EI}_{2} \alpha^{2} \int_{0}^{L}\left[\frac{\partial^{2} U_{2}(x)}{\partial x^{2}}\right]^{2} \mathrm{~d} x$.

Differentiating $U_{n}(x)$ in Eq. (20) twice with respect to $x$ and using $\xi=1.8751$, this integral can be obtains as total potential energy of the cantilever DWCNT, $P_{\mathrm{c}}=P_{1}+P_{2}$

$P_{\mathrm{c}}=12.3623 a^{2} \frac{E}{L^{3}}\left(I_{1}+I_{2}\right)$.

Since the potential energy of the equivalent SDOF oscillator is $(1 / 2) k_{\mathrm{eq} \alpha}^{2}$, from the previous equation, we have

$k_{\mathrm{eq}}=12.3623 \frac{E}{L^{3}}\left(I_{1}+I_{2}\right)$.

The value of the added mass is $M$ in outer wall DWCNT of cantilever. Assuming harmonic motion, i.e. $u(x, t)=$ $U(x) \exp (\mathrm{i} \omega \mathrm{t})$, where $\omega$ is the frequency, the kinetic energy of the inner walled DWCNT can be obtained as

$K_{1}=\frac{\omega^{2}}{2} \int_{0}^{L} \rho A_{1} U_{1}^{2}(x) \mathrm{d} x=\frac{\omega^{2} a^{2}}{2} \rho A_{1} L$.

The kinetic energy of the outer walled DWCNT can be obtained as

$$
\begin{aligned}
K_{2} & =\frac{\omega^{2}}{2} \int_{0}^{L} \rho A_{2} U_{2}^{2}(x) \mathrm{d} x+\frac{\omega^{2}}{2} M U_{2}^{2}(L) \\
& =\frac{\omega^{2} a^{2}}{2}\left(\rho A_{2} L+4 M\right) .
\end{aligned}
$$

The total kinetic energy of the DWCNT can be obtained as 
$K_{\mathrm{c}}=K_{1}+K_{2}=\frac{\omega^{2} a^{2}}{2}\left[\rho\left(A_{1}+A_{2}\right) L+4 M\right]$.

Since the kinetic energy of the equivalent SDOF oscillator is $(1 / 2) m_{\mathrm{eq}} \omega^{2} \alpha^{2}$, we have

$m_{\mathrm{eq}}=\left[\rho\left(A_{1}+A_{2}\right) L+4 M\right]$.

Substituting values in Eq. (18), the resultant frequency of the DWCNT with attached mass can be obtained by (Chowdhury et al. 2009, 2011)

$f_{n}=\frac{1}{2 \pi} \sqrt{\frac{k_{\mathrm{eq}}}{m_{\mathrm{eq}}}}=\frac{1}{2 \pi} \sqrt{\frac{12.3623 \frac{E}{L^{3}}\left(I_{1}+I_{2}\right)}{\rho\left(A_{1}+A_{2}\right) L+4 M}}$

$f_{n}=\frac{1}{2 \pi} \frac{\alpha_{k} \beta}{\sqrt{1+\alpha_{m} \Delta M}}$,

where $\quad \alpha_{k}=\sqrt{12.3623}=3.5160, \quad \beta=\sqrt{\frac{\mathrm{EI}}{\rho\left(A_{1}+A_{2}\right) L^{4}}}$,
$\Delta M=\frac{M}{\rho\left(A_{1}+A_{2}\right) L}$ and $\alpha_{m}=4$

$\Delta M$ is the relative mass change.

The resonant frequency for a cantilevered DWCNT without any added mass is obtained by substituting $\Delta M=0$ in Eq. (32) as

$f_{\text {on }}=\frac{1}{2 \pi} \alpha_{k} \beta$.

Bridged DWCNT with a biological object at the midpoint

In case of a bridged DWCNT the maximum deflection occurs under the added mass at center of the length $=L / 2$.

The bridged beam can be found by explaining the equation, $\cos \xi \cosh \xi-1=0, \xi_{1}=4.7300$, the vibration mode can be expressed as

$$
\begin{aligned}
U_{n}(x)= & \left(\cosh \xi_{n} \frac{x}{L}-\cos \xi_{n} \frac{x}{L}\right)-\left(\frac{\cosh \xi_{n}-\cos \xi_{n}}{\sinh \xi_{n}+\sin \xi_{n}}\right) \\
& \times\left(\sinh \xi_{n} \frac{x}{L}-\sin \xi_{n} \frac{x}{L}\right) .
\end{aligned}
$$

The mode shape is normalized according to Eq. (34) same like as cantilever.

From the total potential energy of the DWCNT, the equivalent stiffness can be obtained as

$$
\begin{aligned}
P_{\mathrm{b}} & =P_{1}+P_{2}=500.5638 a^{2} \frac{E}{L^{3}}\left(I_{1}+I_{2}\right) \\
k_{\mathrm{eq}} & =500.5638 \frac{E}{L^{3}}\left(I_{1}+I_{2}\right) .
\end{aligned}
$$

The total kinetic energy of the bridged DWCNT can be obtained as
$K_{\mathrm{b}}=K_{1}+K_{2}=\frac{\omega^{2} a^{2}}{2}\left[\rho\left(A_{1}+A_{2}\right) L+2.52220 M\right]$

$m_{\mathrm{eq}}=\left[\rho\left(A_{1}+A_{2}\right) L+2.52220 M\right]$.

The resultant frequency of the DWCNT with attached mass can be obtained by substituting value in Eq. (18)

$$
\begin{aligned}
f_{n} & =\frac{1}{2 \pi} \sqrt{\frac{k_{\mathrm{eq}}}{m_{\mathrm{eq}}}}=\frac{1}{2 \pi} \sqrt{\frac{500.5638 \frac{E}{L^{3}}\left(I_{1}+I_{2}\right)}{\rho\left(A_{1}+A_{2}\right) L+2.52220 M}} \\
& =\frac{1}{2 \pi} \frac{\alpha_{k} \beta}{\sqrt{1+\alpha_{m} \Delta M}},
\end{aligned}
$$

where $\quad \alpha_{k}=\sqrt{500.5638}=22.3732, \quad \beta=\sqrt{\frac{\mathrm{EI}}{\rho\left(A_{1}+A_{2}\right) L^{4}}}$, $\Delta M=\frac{M}{\rho\left(A_{1}+A_{2}\right) L}$ and $\alpha_{m}=2.52220$.

Figure 5 shown the bridged DWCNT resonator of length $L$ with an attached biomass Alanine with amino terminal residue with a of $1.213071 \mathrm{E}^{-22} \mathrm{~g}$ mass at the center.

\section{Mass detection and sensitivity calculation of DWCNT}

The expressions of the natural frequencies of the mass loaded DWCNT are now used to obtain the mass based on the frequency shift (Patel and Joshi 2014); (Chowdhury et al. 2009, 2011; Li and Chou 2004; Yang et al. 2006). Combining (32) and (33), one obtains the relationship between the resonant frequencies as

$f_{n}=\frac{f_{\text {on }}}{\sqrt{1+\alpha_{m} \Delta M}}$

$\Delta f=f_{\text {on }}-f_{n}=f_{\text {on }}-\frac{f_{\text {on }}}{\sqrt{1+\alpha_{m} \Delta M}}$.

Rearranging gives the expression

$\Delta M=\frac{1}{\alpha_{m}\left(1-\left(\Delta f / f_{\text {on }}\right)\right)^{2}}-\frac{1}{\alpha_{m}}$

This equation completely relates the change in mass with the frequency shift. The actual value of the added mass can be obtained from (42) as

$M=\frac{\rho\left(A_{1}+A_{2}\right) L}{\alpha_{m}} \frac{\left(\alpha_{k}^{2} \beta^{2}\right)}{\left(\alpha_{k} \beta-2 \pi \Delta f\right)^{2}}-\frac{\rho\left(A_{1}+A_{2}\right) L}{\alpha_{m}}$.

This is the common equation which completely relates the added mass and the frequency shift. The constants appearing in this equation can be summarized as

$S=\frac{\partial M}{\partial \Delta f}=\frac{\rho\left(A_{1}+A_{2}\right) L}{\alpha_{m}} \frac{4 \pi\left(\alpha_{k}^{2} \beta^{2}\right)}{\left(\alpha_{k} \beta-2 \pi \Delta f\right)^{3}}$.

It is observed that the mass-detection sensitivity of a DWCNT-based biomass nano sensor is a nonlinear 
Fig. 5 Bridged DWCNT resonator of length $L$ with an attached biomass Alanine with amino terminal residue at the center

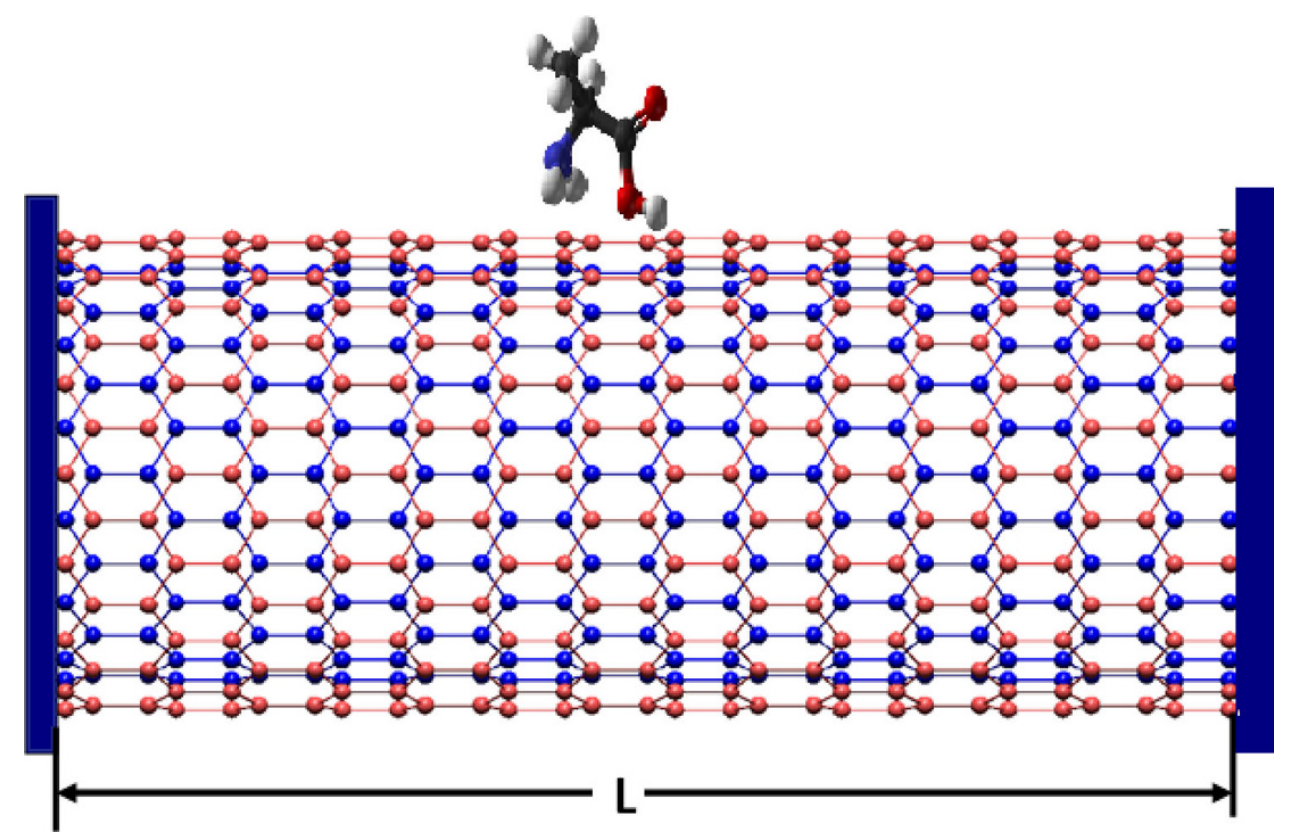

function of the frequency shift. Expanding the sensitivity in Eq. (44) using Taylor series in the minimum sensitivity, can be obtained by taking $\lim \Delta f \rightarrow 0$

$S_{\min }=\frac{\rho\left(A_{1}+A_{2}\right) L}{\alpha_{m}} \frac{4 \pi}{\left(\alpha_{k} \beta\right)}$.

Applying this equation for the cantilevered and bridged DWCNT, the minimum sensitivities can be obtained as

$S_{\text {cantilever }}=\frac{4 \pi}{14.064} \frac{\rho\left(A_{1}+A_{2}\right) L}{\beta}$ and

$S_{\text {bridged }}=\frac{4 \pi}{56.430} \frac{\rho\left(A_{1}+A_{2}\right) L}{\beta}$.

From this, it can be resolved that the cantilever DWCNT sensor is about four times more sensitive compared to the bridged DWCNT (Chowdhury et al. 2011).

\section{Validation of the model}

To verify the model, for the case of DWCNT with the bridged boundary condition, the authors have compared the present model results with $\mathrm{Li}$ and Chou in Table 2. It is clearly observed from Fig. 6 that the results of the present model are in close vicinity to those of $\mathrm{Li}$ and Chou (2004) which suggests that the given model can be further explored.

\section{Results and discussion}

As suggested by Adhikari et al. (2011), Cantilever sensors are four times more sensitive than bridged sensors. Hence, for the purpose of analysis the authors have considered cantilever sensors only. Six different type of DWCNTs, i.e. three types of zigzag $(8,8) @(6,6),(10,10) @(5,5) \operatorname{and}(7,7) @$ $(4,4)$ and armchair $(14,0) @(10,0),(18,0) @(9,0)$ and $(12,0)$ @ $(7,0)$ are considered for analysis.

In this paper, the vibration of the cantilever doublewalled carbon nanotube (DWCNT) with attached biological object on the tip has been investigated in the view of developing the sensor. The sensor is to be developed based on DWCNT so as to be able to identify the viruses, bacteria and other biological objects that may be attached to outer wall of the nanotube. In order to perform the vibration analysis of the system information about the mass of various biological object is required which is indicated in Table 1.

Tables 3 and 4 show the percentage error in frequency shift for various values of the attached molecules. The percentage error is calculated by taken the difference between results obtained using the Atomic finite element simulation and analytical approach. Table 5 signifies the resonant frequency and frequency shift of cantilever DWCNT due to Coronaviridae virus. Table 6 shows resonant frequency for cantilever DWCNT using biological mass Bartonella Bacilliformis.

As indicated in Fig. 7a-d, four biological objects with mass in Zeptogram scales have been used to simulate the vibration responses of zigzag and armchair DWCNT based biosensors:

1. Alanine with Amino terminal residue: Alanine is an $\alpha$-amino acid with the chemical formula $\mathrm{CH}_{3} \cdot \mathrm{CH}$ $\left(\mathrm{NH}_{2}\right) \mathrm{COOH}$. It is one of the 22 proteinogenic amino acids, which are considered as the building blocks of proteins. It is also well known as 2-aminopropanoic 
Table 2 Comparison of fundamental frequency of DWCNT and theoretical approach

\begin{tabular}{|c|c|c|c|c|c|c|c|c|c|c|c|}
\hline \multirow[t]{3}{*}{ Nano tube type } & \multirow[t]{3}{*}{$L(\mathrm{~nm})$} & \multicolumn{10}{|c|}{ Fundamental frequency $(\mathrm{THz})$} \\
\hline & & \multicolumn{5}{|c|}{ Present model (mode shape) } & \multicolumn{5}{|c|}{ Analytical model (Li and Chou 2004) } \\
\hline & & 1 & 2 & 3 & 4 & 5 & 1 & 2 & 3 & 4 & 5 \\
\hline \multirow[t]{3}{*}{ Zigzag } & 3.9 & 0.9400 & 0.9410 & 1.3700 & 1.3767 & 1.6226 & 0.9446 & 0.9450 & 1.3687 & 1.3697 & 1.6139 \\
\hline & 5.6 & 0.5930 & 0.5940 & 1.1810 & 1.1940 & 1.2900 & 0.5774 & 0.5775 & 1.1789 & 1.1797 & 1.2750 \\
\hline & 8.0 & 0.3443 & 0.3443 & 0.7610 & 0.7620 & 0.9453 & 0.3337 & 0.3337 & 0.7573 & 0.7576 & 0.9263 \\
\hline \multirow[t]{3}{*}{ Arm chair } & 4.1 & 0.9478 & 0.9480 & 1.5650 & 1.5697 & 1.8121 & 0.9276 & 0.9276 & 1.5454 & 1.5493 & 1.6512 \\
\hline & 5.5 & 0.6410 & 0.6440 & 1.2922 & 1.3922 & 1.4036 & 0.7355 & 0.7356 & 1.4322 & 1.4996 & 1.5036 \\
\hline & 8.0 & 0.3550 & 0.3555 & 0.7870 & 0.7877 & 0.9121 & 0.3323 & 0.3323 & 0.7670 & 0.7671 & 0.8932 \\
\hline
\end{tabular}

Fig. 6 Comparison of frequency between $\mathrm{Li}$ and $\mathrm{Chou}$ (2004) and current model for different length and types of DWCNT

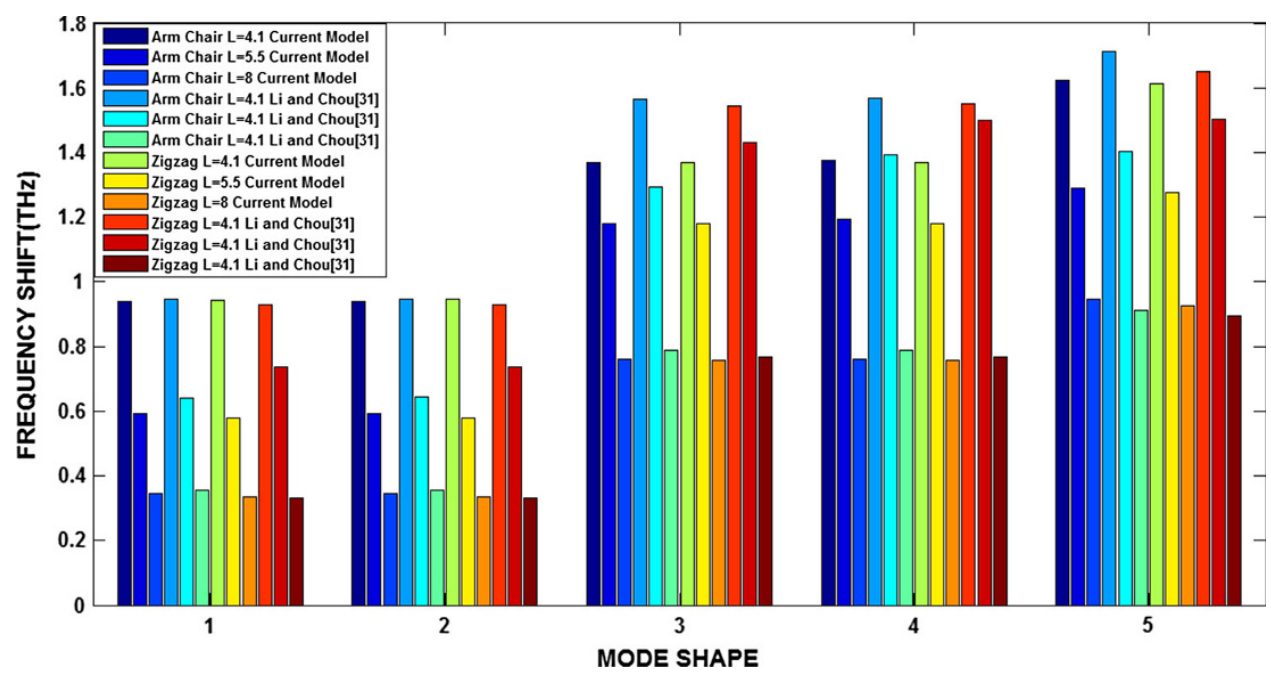

acid. The $\alpha$ carbon atom of alanine is bound with a methyl group $\left(-\mathrm{CH}_{3}\right)$, making it one of the simplest $\alpha$-amino acids with respect to molecular structure and also resulting in alanine's being classified as an aliphatic amino acid. The methyl group of alanine is non-reactive and is thus almost never directly involved in protein function. It occurs in bacterial cell walls and in some peptide antibiotics. Alanine can be manufactured in the body from branched chain amino acids such as valine, leucine and isoleucine and it plays a key role in glucose-alanine cycle between tissues and liver. In muscle and other tissues that degrade amino acids for fuel, amino groups are collected by transamination.

2. Deoxyadeonosine with free residue: Deoxyadenosine refers to a deoxyribonucleoside (a nucleoside compo- nent of DNA, composed of adenosine and deoxyribose) with the chemical formula $\mathrm{C}_{10} \mathrm{H}_{13} \mathrm{~N}_{5} \mathrm{O}_{3}$. It is derived from the nucleoside adenosine, which differs by the replacement of a hydroxyl group $(-\mathrm{OH})$ by hydrogen $(-\mathrm{H})$ in the ribose part of the molecule. This modification prevents the formation of phosphodiester linkages which are needed for the completion of nucleic acid chains. A deoxyribonucleoside is a type of nucleoside including deoxyribose as a component.

3. Coronaviridae: Coronaviridae is a family of enveloped, positive-stranded RNA viruses. The viral genome is 26-32 kb in length. Virions are spherical, 120-160 nm across (Coronavirinae), bacilliform and 170-200 by 75-88 nm (Bafinivirus) or found as a mixture of both, with bacilliform particles characteristically bent into crescents (Torovirus). The particles are typically 
Table 3 Percentage error in the frequency shift for cantilever DWCNT with different value of 08 molecules alanine with amino terminal residue Alanine with amino terminal residue

\begin{tabular}{|c|c|c|c|c|c|c|}
\hline \multirow[t]{2}{*}{ Mass $(\mathrm{Zg})$} & \multicolumn{3}{|c|}{ Frequency shift $(\mathrm{Hz})$} & \multicolumn{3}{|c|}{ Percentage error $(\%)$} \\
\hline & $\begin{array}{l}\text { DWCNT } \\
(8,8) @(6,6)\end{array}$ & $\begin{array}{l}\text { DWCNT } \\
(10,10) @(5,5)\end{array}$ & $\begin{array}{l}\text { DWCNT } \\
(7,7) @(4,4)\end{array}$ & $\begin{array}{l}\text { DWCNT } \\
(8,8) @(6,6)\end{array}$ & $\begin{array}{l}\text { DWCNT } \\
(10,10) @(5,5)\end{array}$ & $\begin{array}{l}\text { DWCNT } \\
(7,7) @(4,4)\end{array}$ \\
\hline 0.121307 & $4.39 \mathrm{E}+07$ & $2.00 \mathrm{E}+07$ & $1.00 \mathrm{E}+07$ & 2.489 & 5.632 & 6.236 \\
\hline 0.242614 & $8.43 \mathrm{E}+07$ & $2.56 \mathrm{E}+07$ & $1.30 \mathrm{E}+07$ & 4.690 & 3.205 & 2.589 \\
\hline 0.363921 & $1.12 \mathrm{E}+08$ & $3.40 \mathrm{E}+07$ & $2.71 \mathrm{E}+07$ & 3.425 & 5.045 & 5.26 \\
\hline 0.485228 & $1.31 \mathrm{E}+08$ & $4.62 \mathrm{E}+07$ & $3.85 \mathrm{E}+07$ & 6.680 & 8.520 & 7.258 \\
\hline 0.606535 & $1.46 \mathrm{E}+08$ & $5.97 \mathrm{E}+07$ & $5.01 \mathrm{E}+07$ & 7.465 & 6.253 & 10.256 \\
\hline 0.727842 & $1.57 \mathrm{E}+08$ & $6.86 \mathrm{E}+07$ & $6.01 \mathrm{E}+07$ & 2.458 & 6.025 & 7.256 \\
\hline 0.849149 & $1.66 \mathrm{E}+08$ & $7.86 \mathrm{E}+07$ & $7.07 \mathrm{E}+07$ & 1.025 & 7.250 & 8.269 \\
\hline 0.970456 & $1.74 \mathrm{E}+08$ & $8.73 \mathrm{E}+07$ & $8.06 \mathrm{E}+07$ & 2.980 & 2.123 & 1.025 \\
\hline \multirow[t]{2}{*}{ Mass $(\mathrm{Zg})$} & \multicolumn{3}{|c|}{ Frequency shift $(\mathrm{Hz})$} & \multicolumn{3}{|c|}{ Percentage error $(\%)$} \\
\hline & $\begin{array}{l}\text { DWCNT } \\
(14,0) @(10,0)\end{array}$ & $\begin{array}{l}\text { DWCNT } \\
(18,0) @(9,0)\end{array}$ & $\begin{array}{l}\text { DWCNT } \\
(12,0) @(7,0)\end{array}$ & $\begin{array}{l}\text { DWCNT } \\
(14,0) @(10,0)\end{array}$ & $\begin{array}{l}\text { DWCNT } \\
(18,0) @(9,0)\end{array}$ & $\begin{array}{l}\text { DWCNT } \\
(12,0) @(7,0)\end{array}$ \\
\hline 0.121307 & $3.00 \mathrm{E}+07$ & $2.13 \mathrm{E}+07$ & $1.10 \mathrm{E}+07$ & 8.691 & 6.358 & 5.360 \\
\hline 0.242614 & $3.96 \mathrm{E}+07$ & $2.98 \mathrm{E}+07$ & $1.90 \mathrm{E}+07$ & 5.798 & 4.236 & 2.369 \\
\hline 0.363921 & $5.43 \mathrm{E}+07$ & $4.71 \mathrm{E}+07$ & $3.21 \mathrm{E}+07$ & 4.236 & 2.456 & 8.236 \\
\hline 0.485228 & $7.25 \mathrm{E}+07$ & $6.50 \mathrm{E}+07$ & $4.59 \mathrm{E}+07$ & 5.236 & 3.211 & 7.025 \\
\hline 0.606535 & $8.64 \mathrm{E}+07$ & $8.22 \mathrm{E}+07$ & $5.83 \mathrm{E}+07$ & 3.236 & 2.365 & 7.025 \\
\hline 0.727842 & $9.74 \mathrm{E}+07$ & $9.13 \mathrm{E}+07$ & $6.52 \mathrm{E}+07$ & 1.986 & 4.045 & 4.236 \\
\hline 0.849149 & $1.06 \mathrm{E}+08$ & $9.89 \mathrm{E}+07$ & $7.43 \mathrm{E}+07$ & 2.368 & 10.23 & 3.023 \\
\hline 0.970456 & $1.14 \mathrm{E}+08$ & $1.05 \mathrm{E}+08$ & $9.53 \mathrm{E}+07$ & 2.358 & 8.230 & 2.780 \\
\hline
\end{tabular}

Table 4 Percentage error in the frequency shift for cantilever DWCNT with different value of 07 molecules Deoxyadeonosine with free residue Deoxyadeonosine with free residue

\begin{tabular}{|c|c|c|c|c|c|c|}
\hline \multirow[t]{2}{*}{ Mass (Zg) } & \multicolumn{3}{|c|}{ Frequency shift $(\mathrm{Hz})$} & \multicolumn{3}{|c|}{ Percentage error $(\%)$} \\
\hline & $\begin{array}{l}\text { DWCNT } \\
(8,8) @(6,6)\end{array}$ & $\begin{array}{l}\text { DWCNT } \\
(10,10) @(5,5)\end{array}$ & $\begin{array}{l}\text { DWCNT } \\
(7,7) @(4,4)\end{array}$ & $\begin{array}{l}\text { DWCNT } \\
(8,8) @(6,6)\end{array}$ & $\begin{array}{l}\text { DWCNT } \\
(10,10) @(5,5)\end{array}$ & $\begin{array}{l}\text { DWCNT } \\
(7,7) @(4,4)\end{array}$ \\
\hline 0.416965 & $1.21 \mathrm{E}+08$ & $3.76 \mathrm{E}+07$ & $4.74 \mathrm{E}+07$ & 7.203 & 2.369 & 2.583 \\
\hline 0.83393 & $1.65 \mathrm{E}+08$ & $7.57 \mathrm{E}+07$ & $8.46 \mathrm{E}+07$ & 10.253 & 3.458 & 3.458 \\
\hline 1.250895 & $1.87 \mathrm{E}+08$ & $9.51 \mathrm{E}+07$ & $1.01 \mathrm{E}+08$ & 6.890 & 5.269 & 6.248 \\
\hline 1.667860 & $2.00 \mathrm{E}+08$ & $1.07 \mathrm{E}+08$ & $1.12 \mathrm{E}+08$ & 3.356 & 4.587 & 6.458 \\
\hline 2.084825 & $2.09 \mathrm{E}+08$ & $1.16 \mathrm{E}+08$ & $1.22 \mathrm{E}+08$ & 4.589 & 8.257 & 1.916 \\
\hline 2.501790 & $2.16 \mathrm{E}+08$ & $1.24 \mathrm{E}+08$ & $1.29 \mathrm{E}+08$ & 7.586 & 1.872 & 2.564 \\
\hline 2.918755 & $2.25 \mathrm{E}+08$ & $1.36 \mathrm{E}+08$ & $1.41 \mathrm{E}+08$ & 5.256 & 2.125 & 9.869 \\
\hline \multirow[t]{2}{*}{ Mass $(\mathrm{Zg})$} & \multicolumn{3}{|c|}{ Frequency shift $(\mathrm{Hz})$} & \multicolumn{3}{|c|}{ Percentage error $(\%)$} \\
\hline & $\begin{array}{l}\text { DWCNT } \\
(14,0) @(10,0)\end{array}$ & $\begin{array}{l}\text { DWCNT } \\
(18,0) @(9,0)\end{array}$ & $\begin{array}{l}\text { DWCNT } \\
(12,0) @(7,0)\end{array}$ & $\begin{array}{l}\text { DWCNT } \\
(14,0) @(10,0)\end{array}$ & $\begin{array}{l}\text { DWCNT } \\
(18,0) @(9,0)\end{array}$ & $\begin{array}{l}\text { DWCNT } \\
(12,0) @(7,0)\end{array}$ \\
\hline 0.416965 & $6.29 \mathrm{E}+07$ & $5.36 \mathrm{E}+07$ & $1.00 \mathrm{E}+07$ & 2.582 & 4.025 & 7.985 \\
\hline 0.83393 & $1.05 \mathrm{E}+08$ & $9.81 \mathrm{E}+07$ & $3.52 \mathrm{E}+07$ & 5.356 & 6.656 & 4.528 \\
\hline 1.250895 & $1.28 \mathrm{E}+08$ & $1.17 \mathrm{E}+08$ & $5.41 \mathrm{E}+07$ & 7.458 & 3.258 & 7.426 \\
\hline 1.667860 & $1.41 \mathrm{E}+08$ & $1.29 \mathrm{E}+08$ & $6.91 \mathrm{E}+07$ & 6.256 & 2.321 & 2.568 \\
\hline 2.084825 & $1.51 \mathrm{E}+08$ & $1.38 \mathrm{E}+08$ & $7.96 \mathrm{E}+07$ & 8.661 & 3.103 & 2.798 \\
\hline 2.501790 & $1.59 \mathrm{E}+08$ & $1.45 \mathrm{E}+08$ & $8.74 \mathrm{E}+07$ & 2.314 & 9.569 & 3.357 \\
\hline 2.918755 & $1.65 \mathrm{E}+08$ & $1.50 \mathrm{E}+08$ & $9.36 \mathrm{E}+07$ & 1.011 & 2.869 & 2.951 \\
\hline
\end{tabular}


Table 5 Resonant frequency and frequency shift of cantilever DWCNT due to Coronaviridae biological object

Coronaviridae cantilever condition

\begin{tabular}{|c|c|c|c|c|c|c|}
\hline \multirow[t]{2}{*}{ Mass (gm) } & \multicolumn{3}{|l|}{ Frequency $(\mathrm{Hz})$} & \multicolumn{3}{|c|}{ Frequency shift $(\mathrm{Hz})$} \\
\hline & $\begin{array}{l}\text { DWCNT } \\
(8,8) @(6,6)\end{array}$ & $\begin{array}{l}\text { DWCNT } \\
(10,10) @(5,5)\end{array}$ & $\begin{array}{l}\text { DWCNT } \\
(7,7) @(4,4)\end{array}$ & $\begin{array}{l}\text { DWCNT } \\
(8,8) @(6,6)\end{array}$ & $\begin{array}{l}\text { DWCNT } \\
(10,10) @(5,5)\end{array}$ & $\begin{array}{l}\text { DWCNT } \\
(7,7) @(4,4)\end{array}$ \\
\hline $1.33 \mathrm{E}-19$ & $3.32 \mathrm{E}+07$ & $3.08 \mathrm{E}+07$ & $3.49 \mathrm{E}+07$ & $2.58782 \mathrm{E}+08$ & $1.61347 \mathrm{E}+08$ & $1.73577 \mathrm{E}+08$ \\
\hline $1.20767 \mathrm{E}-18$ & $1.11 \mathrm{E}+07$ & $1.02 \mathrm{E}+07$ & $1.16 \mathrm{E}+07$ & $2.80968 \mathrm{E}+08$ & $1.81883 \mathrm{E}+08$ & $1.96850 \mathrm{E}+08$ \\
\hline $2.28193 \mathrm{E}-18$ & $8.05 \mathrm{E}+06$ & $7.46 \mathrm{E}+06$ & $8.44 \mathrm{E}+06$ & $2.83981 \mathrm{E}+08$ & $1.84675 \mathrm{E}+08$ & $2.00010 \mathrm{E}+08$ \\
\hline $3.3562 \mathrm{E}-18$ & $6.64 \mathrm{E}+06$ & $6.15 \mathrm{E}+06$ & $6.96 \mathrm{E}+06$ & $2.85393 \mathrm{E}+08$ & $1.85982 \mathrm{E}+08$ & $2.01491 \mathrm{E}+08$ \\
\hline $4.43047 \mathrm{E}-18$ & $5.78 \mathrm{E}+06$ & $5.35 \mathrm{E}+06$ & $6.06 \mathrm{E}+06$ & $2.86253 \mathrm{E}+08$ & $1.86779 \mathrm{E}+08$ & $2.02393 \mathrm{E}+08$ \\
\hline $5.50473 \mathrm{E}-18$ & $5.18 \mathrm{E}+06$ & $4.80 \mathrm{E}+06$ & $5.43 \mathrm{E}+06$ & $2.86847 \mathrm{E}+08$ & $1.87329 \mathrm{E}+08$ & $2.03016 \mathrm{E}+08$ \\
\hline $6.579 \mathrm{E}-18$ & $4.74 \mathrm{E}+06$ & $4.39 \mathrm{E}+06$ & $4.97 \mathrm{E}+06$ & $2.87289 \mathrm{E}+08$ & $1.87739 \mathrm{E}+08$ & $2.03479 \mathrm{E}+08$ \\
\hline \multirow[t]{2}{*}{$\overline{\text { Mass }(\mathrm{g})}$} & \multicolumn{3}{|l|}{ Frequency (Hz) } & \multicolumn{3}{|c|}{ Frequency shift $(\mathrm{Hz})$} \\
\hline & $\begin{array}{l}\text { DWCNT } \\
(14,0) @(10,0)\end{array}$ & $\begin{array}{l}\text { DWCNT } \\
(18,0) @(9,0)\end{array}$ & $\begin{array}{l}\text { DWCNT } \\
(12,0) @(7,0)\end{array}$ & $\begin{array}{l}\text { DWCNT } \\
(14,0) @(10,0)\end{array}$ & $\begin{array}{l}\text { DWCNT } \\
(18,0) @(9,0)\end{array}$ & $\begin{array}{l}\text { DWCNT } \\
(12,0) @(7,0)\end{array}$ \\
\hline $1.33 \mathrm{E}-19$ & $3.64 \mathrm{E}+07$ & $3.33 \mathrm{E}+07$ & $3.84 \mathrm{E}+07$ & $2.05 \mathrm{E}+08$ & $1.86 \mathrm{E}+08$ & $1.36 \mathrm{E}+08$ \\
\hline $1.20767 \mathrm{E}-18$ & $1.21 \mathrm{E}+07$ & $1.11 \mathrm{E}+07$ & $1.28 \mathrm{E}+07$ & $2.29 \mathrm{E}+08$ & $2.09 \mathrm{E}+08$ & $1.62 \mathrm{E}+08$ \\
\hline $2.28193 \mathrm{E}-18$ & $8.82 \mathrm{E}+06$ & $8.08 \mathrm{E}+06$ & $9.29 \mathrm{E}+06$ & $2.32 \mathrm{E}+08$ & $2.12 \mathrm{E}+08$ & $1.65 \mathrm{E}+08$ \\
\hline $3.3562 \mathrm{E}-18$ & $7.28 \mathrm{E}+06$ & $6.67 \mathrm{E}+06$ & $1.75 \mathrm{E}+07$ & $2.34 \mathrm{E}+08$ & $2.13 \mathrm{E}+08$ & $1.57 \mathrm{E}+08$ \\
\hline $4.43047 \mathrm{E}-18$ & $6.33 \mathrm{E}+06$ & $5.80 \mathrm{E}+06$ & $7.66 \mathrm{E}+06$ & $2.35 \mathrm{E}+08$ & $2.14 \mathrm{E}+08$ & $1.67 \mathrm{E}+08$ \\
\hline $5.50473 \mathrm{E}-18$ & $5.68 \mathrm{E}+06$ & $5.21 \mathrm{E}+06$ & $5.99 \mathrm{E}+06$ & $2.35 \mathrm{E}+08$ & $2.14 \mathrm{E}+08$ & $1.68 \mathrm{E}+08$ \\
\hline $6.579 \mathrm{E}-18$ & $5.20 \mathrm{E}+06$ & $4.76 \mathrm{E}+06$ & $5.47 \mathrm{E}+06$ & $2.36 \mathrm{E}+08$ & $2.15 \mathrm{E}+08$ & $1.69 \mathrm{E}+08$ \\
\hline
\end{tabular}

Table 6 Resonant frequency for cantilever DWCNT using biological mass Bartonella Bacilliformis

\begin{tabular}{|c|c|c|c|c|c|c|}
\hline \multicolumn{7}{|c|}{ Bartonella Bacilliformis } \\
\hline \multirow[t]{2}{*}{ Mass (g) } & \multicolumn{6}{|c|}{ Frequency (Hz)_cantilever condition } \\
\hline & $\begin{array}{l}\text { DWCNT } \\
(8,8) @(6,6)\end{array}$ & $\begin{array}{l}\text { DWCNT } \\
(10,10) @(5,5)\end{array}$ & $\begin{array}{l}\text { DWCNT } \\
(7,7) @(4,4)\end{array}$ & $\begin{array}{l}\text { DWCNT } \\
(14,0) @(10,0)\end{array}$ & $\begin{array}{l}\text { DWCNT } \\
(18,0) @(9,0)\end{array}$ & $\begin{array}{l}\text { DWCNT } \\
(12,0) @(7,0)\end{array}$ \\
\hline $5.400000 \mathrm{E}-14$ & $5.23 \mathrm{E}+04$ & $4.85 \mathrm{E}+04$ & $5.49 \mathrm{E}+04$ & $5.74 \mathrm{E}+04$ & $5.26 \mathrm{E}+04$ & $6.04 \mathrm{E}+04$ \\
\hline $1.529833 \mathrm{E}-13$ & $3.11 \mathrm{E}+04$ & $2.88 \mathrm{E}+04$ & $3.26 \mathrm{E}+04$ & $3.41 \mathrm{E}+04$ & $3.12 \mathrm{E}+04$ & $3.59 \mathrm{E}+04$ \\
\hline $2.519667 \mathrm{E}-13$ & $2.42 \mathrm{E}+04$ & $2.24 \mathrm{E}+04$ & $2.54 \mathrm{E}+04$ & $2.66 \mathrm{E}+04$ & $2.43 \mathrm{E}+04$ & $2.80 \mathrm{E}+04$ \\
\hline $3.509500 \mathrm{E}-13$ & $2.05 \mathrm{E}+04$ & $1.90 \mathrm{E}+04$ & $2.15 \mathrm{E}+04$ & $2.25 \mathrm{E}+04$ & $2.06 \mathrm{E}+04$ & $2.37 \mathrm{E}+04$ \\
\hline $4.499333 \mathrm{E}-13$ & $1.81 \mathrm{E}+04$ & $1.68 \mathrm{E}+04$ & $1.90 \mathrm{E}+04$ & $1.99 \mathrm{E}+04$ & $1.82 \mathrm{E}+04$ & $2.09 \mathrm{E}+04$ \\
\hline $5.489167 \mathrm{E}-13$ & $1.64 \mathrm{E}+04$ & $1.52 \mathrm{E}+04$ & $1.72 \mathrm{E}+04$ & $1.80 \mathrm{E}+04$ & $1.65 \mathrm{E}+04$ & $1.90 \mathrm{E}+04$ \\
\hline $6.479000 \mathrm{E}-13$ & $1.51 \mathrm{E}+04$ & $1.40 \mathrm{E}+04$ & $1.58 \mathrm{E}+04$ & $1.66 \mathrm{E}+04$ & $1.52 \mathrm{E}+04$ & $1.74 \mathrm{E}+04$ \\
\hline
\end{tabular}

decorated with large $(\sim 20 \mathrm{~nm})$, club- or petal-shaped surface projections (the "peplomers" or "spikes"), which in electron micrographs of spherical particles create an image reminiscent of the solar corona.
4. Bartonella bacilliformis: Bartonella bacilliformis is a proteobacterium, gram negative aerobic, pleomorphic, flagellated, motile, coccobacillary, 2-3 $\mu \mathrm{m}$ large and $0.2-0.5 \mu \mathrm{m}$ wide and facultative intracellular bacterium. 


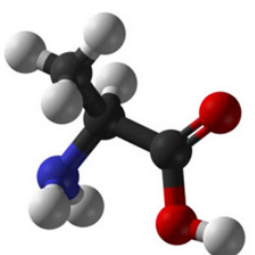

(a)

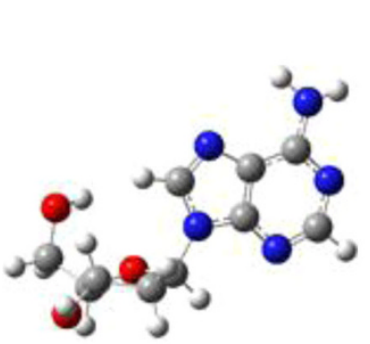

(b)

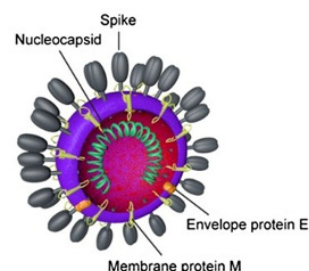

(c)

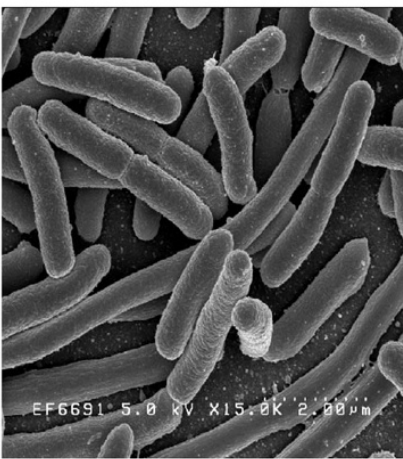

(d)
Fig. 7 a Alanine with amino terminal residue with a mass of $1.213071 \mathrm{E}^{-22} \mathrm{~g}$. DWCNT is loaded with up to 08 molecules of the same type. b Deoxyadeonosine with free residue with a mass of $4.16965 \mathrm{E}^{-22} \mathrm{~g}$. DWCNT is loaded with up to 07 molecules of the same type. c Coronavirus virion structure (Belouzard et al. 2012) d Bartonella bacilliformis (Proteobacteria) (NIAID, NIH Source)

It is endemic in some areas of Peru. The bacterium is transmitted by sandflies of genus Lutzomyia.

Six different type of DWCNTs, i.e. three different type of zigzag (8,8)@(6,6), (10,10)@(5,5)and(7,7)@(4,4) and armchair (14,0)@(10,0), (18,0)@(9,0) and $(12,0) @(7,0)$
Table 7 Mass sensitivity of cantilevered DWCNT

\begin{tabular}{llll}
\hline DWCNT type & $\begin{array}{l}\text { Outer diameter } \\
(\mathrm{nm})\end{array}$ & $\begin{array}{l}\text { Inner diameter } \\
(\mathrm{nm})\end{array}$ & $\begin{array}{l}\text { Sensitivity } \\
(\mathrm{zg} / \mathrm{GHz})\end{array}$ \\
\hline$(8,8) @(6,6)$ & 10.78 & 8.092 & 0.1424 \\
$(10,10) @(5,5)$ & 13.42 & 6.74 & 0.1221 \\
$(7,7) @(4,4)$ & 9.43 & 5.39 & 0.1011 \\
$(14,0) @(10,0)$ & 10.81 & 7.78 & 0.1359 \\
$(18,0) @(9,0$ & 14.012 & 7.0063 & 0.1251 \\
$(12,0) @(7,0)$ & 9.341 & 5.44 & 0.0989 \\
\hline
\end{tabular}

length $25 \mathrm{~nm}$ are loaded with 08 molecules of alanine with amino terminal residue, 07 molecules of deoxyadeonosine with free residue, 07 molecules of Coronaviridae and 07 molecules of Bartonella Bacilliformis and considered for analysis.

The sensitivities of six cantilevered DWCNT are calculated and represented in Table 7. It is clearly observed that zigzag DWCNTs possess better mass sensitivities as compared to armchair DWCNTs. These sensitivities are calculated using Eq. (46).

Figure 8 shows the shifts in the resonant frequency due to the attached masses ( 08 molecules of alanine with amino terminal) for the cantilever, zigzag and armchair DWCNT. It can be visualized form that a higher frequency shift is observed for zigzag DWCNT $(8,8) @(6,6)$ with the increase in the attached molecules of the biological object. Further a gradual reduction in the frequency shift is observed for other types of DWCNTs.
Fig. 8 Frequency shift of cantilever DWCNT due to 08 molecules of alanine with amino terminal vs. mass $(\mathrm{Zg})$

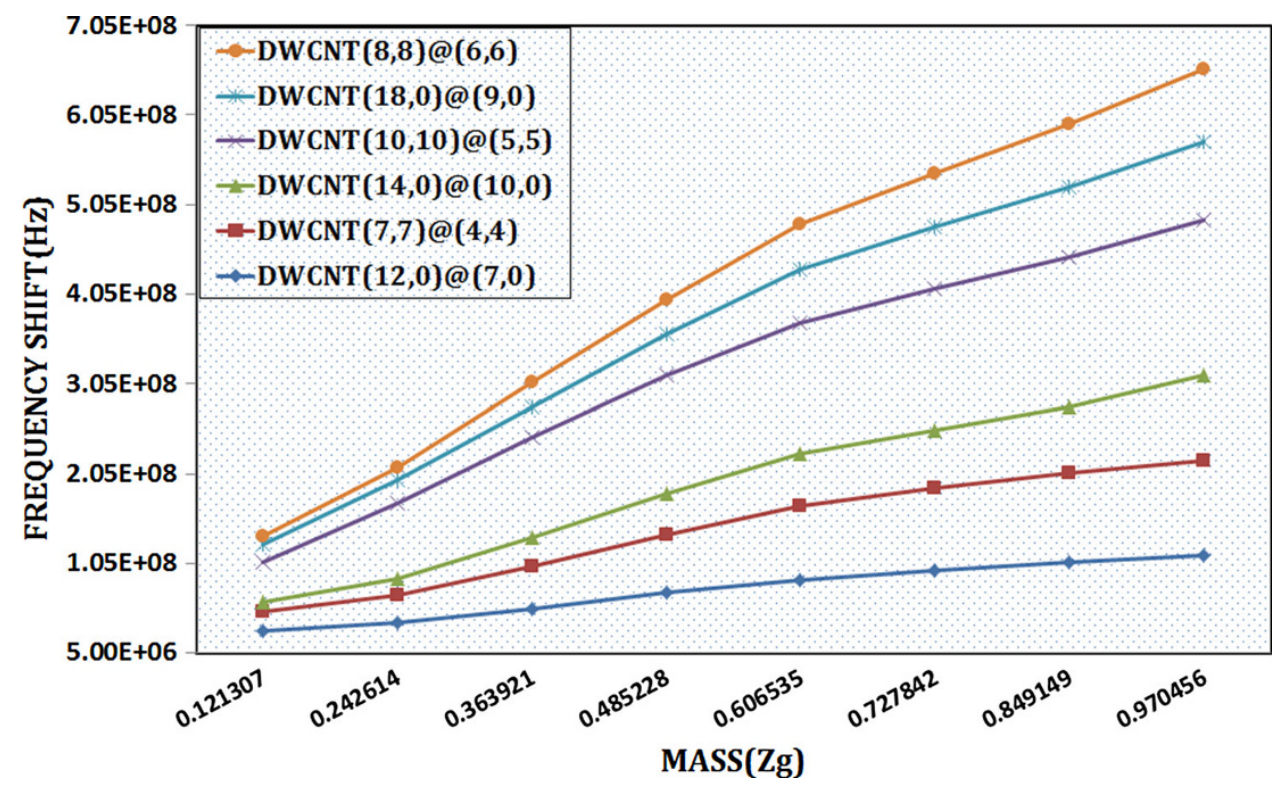




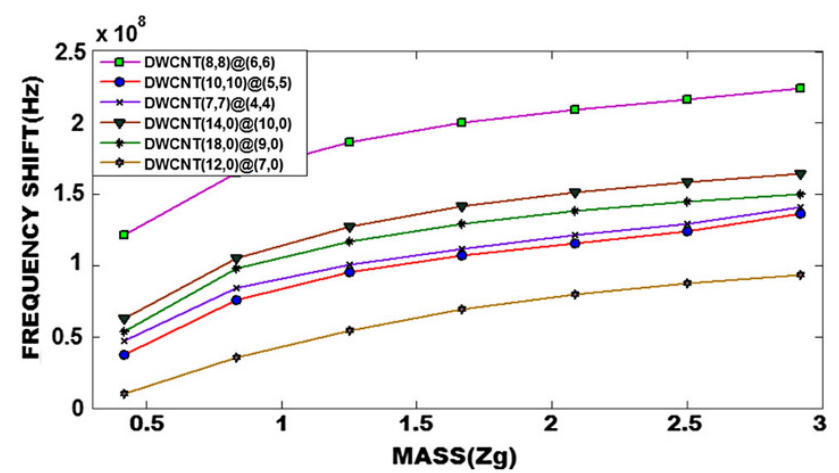

(a)

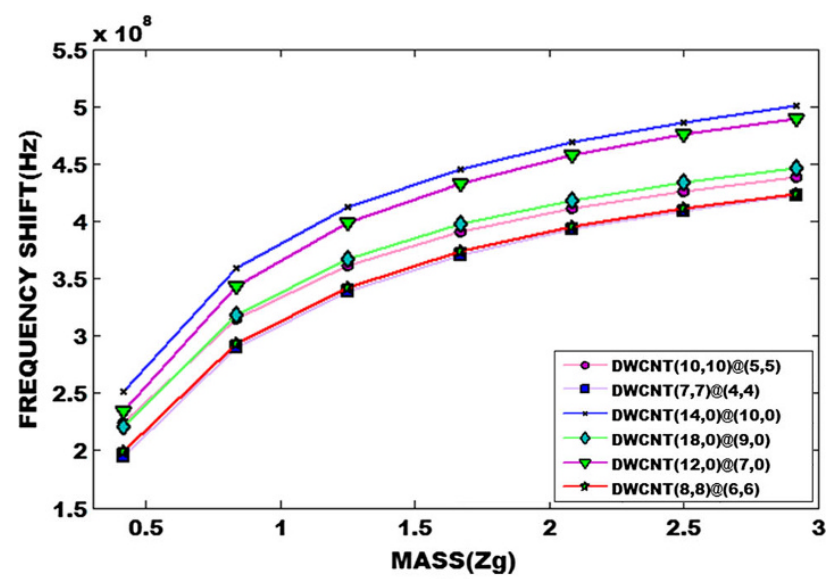

(b)

Fig. 9 a Frequency shift of cantilever zigzag and armchair DWCNT due to 07 molecules of deoxyadeonosine residue vs. mass $(\mathrm{Zg})$. b Frequency shift bridge zigzag and armchair DWCNT due to 07 molecules of deoxyadeonosine residue vs. mass $(\mathrm{Zg})$

Figure 9a, b shows the shifts in the resonant frequency due to the attached masses (07 molecules of deoxyadeonosine) for the cantilever (zigzag and armchair) and bridged (zigzag and armchair) DWCNT. Similarly, Fig. 10 shows frequency shift due to $07 \mathrm{~mol}-$ ecules of deoxyadenosine residue vs. Zigzag and Armchair type of DWCNT. In both the cases a higher frequency shift is observed in cantilever DWCNT $(8,8) @(6,6)$.

Figures 11 and 12 show frequency shift due to 07 molecules of Coronaviridae Bartonella Bacilliformis, respectively. The general tread is similar in both the cases with the maximum shift for zigzag $(8,8) @(6,6)$ CNTs, whereas the maximum shift is obtained for

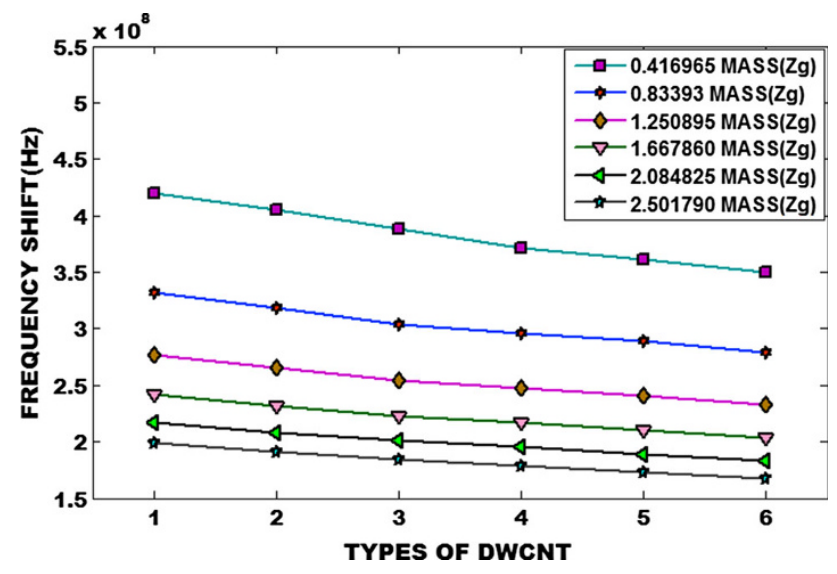

Fig. 10 Resonant frequency shift due to deoxyadrenosine residue 07 molecules vs. Zigzag and Armchair type of DWCNT

$(14,0) @(10,0)$ in case of armchair DWCNT. The reason for it can be attributed to the change in the orientation of the bonds in CNT which further leads to a change in stiffness variation and hence a change in the frequency shift. Also the sensitivity values given in Table 7 clearly suggest that zigzag CNTs are better candidates for sensing the viruses and biological objects as its sensitivity is $0.1424 \mathrm{Zg} / \mathrm{GHz}$.

\section{Conclusion}

The use of double-walled carbon nanotube-based biomass sensors for sensing Zeptogram scale mass has been investigated in this study. The shift in the resonant frequency due to the change in the attached mass has been used as a parameter for exploring DWCNT as a bio sensor. The following conclusions can be drawn:

1. Cantilever configurations are four times more sensitive than bridged configurations.

2. A higher frequency shift is observed for zigzag DWCNT $(8,8) @(6,6)$ type of nanotube with the increase in the attached molecules of four the biological objects.

3. A greater amount of shift is observed for the molecule of alanine with amino terminal residue which has a 
Fig. 11 Resonant frequency shift of cantilever Zigzag and Armchair type of DWCNT vs. Coronaviridae 07 molecules biomass

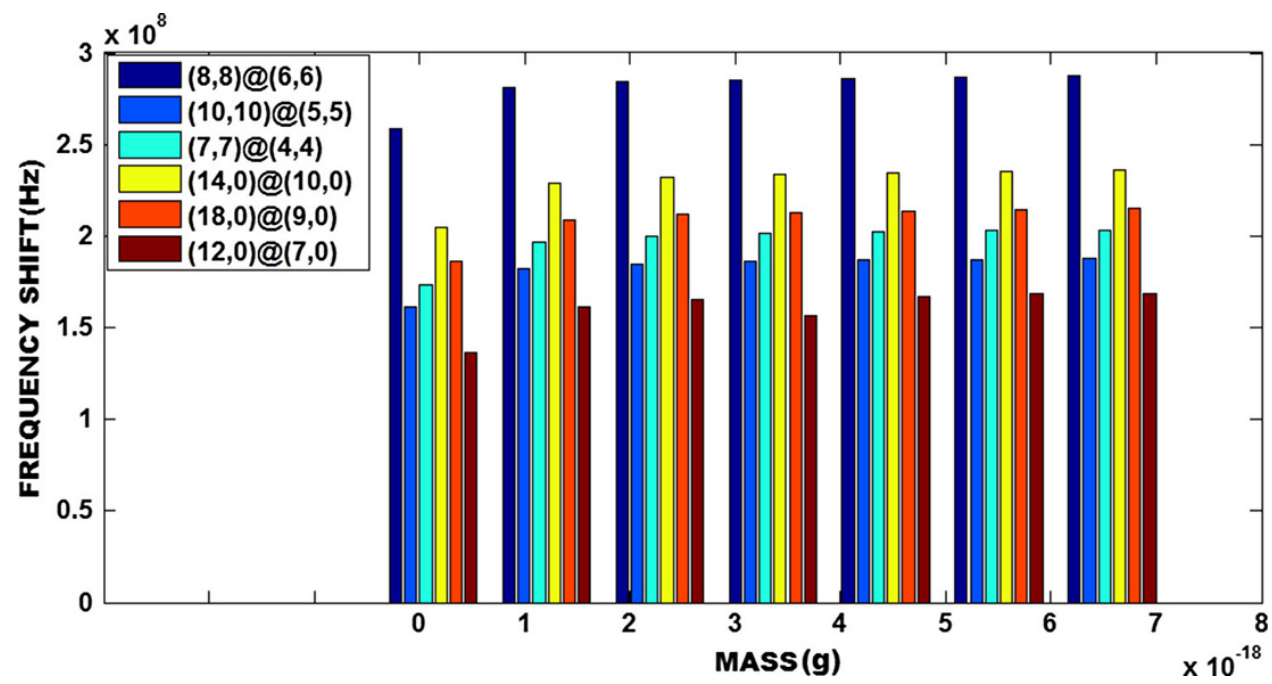

Fig. 12 Frequency shift of Cantilever DWCNT Zigzag and Armchair type of DWCNT vs. Bartonella Bacilliformis 07 molecules

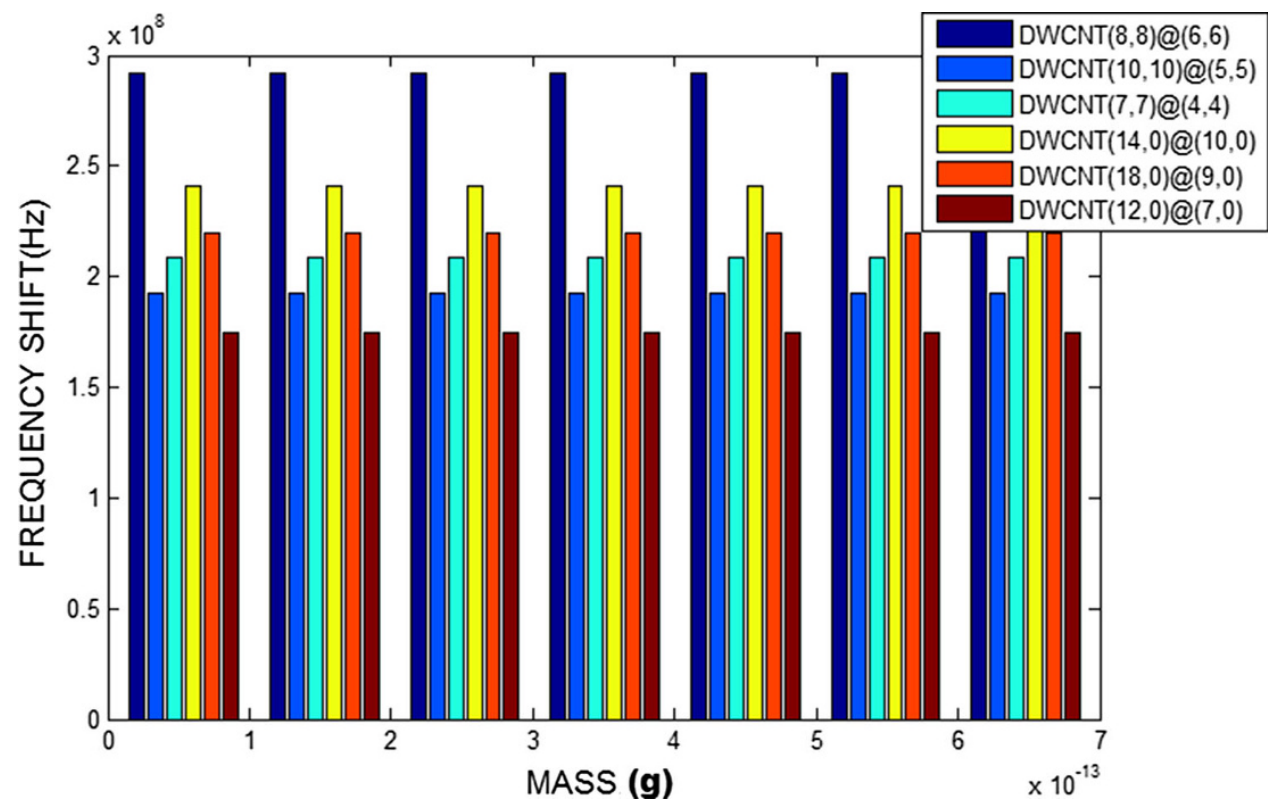

smaller mass as compared to the deoxyadenosine with free residue, Coronaviridae and Bartonella Bacilliformis.

4. Based on the sensitivity and the frequency shift it can be concluded that cantilever zigzag DWCNTs are better candidates for detecting the biological objects.

Acknowledgments The authors would like to acknowledge the DST Grant no. SB/FTP/ETA-106/2013, provided by Department of Science and Technology, Science and Engineering Research Board, Government of India.

Open Access This article is distributed under the terms of the Creative Commons Attribution License which permits any use, distribution, and reproduction in any medium, provided the original author(s) and the source are credited.

\section{References}

Ajayan P (1999) Nanotubes from carbon. Chem Rev 99(7):1787 Ajayan P, Charlier J, Rinzler A (1999) Carbon nanotubes: from macromolecules to nanotechnology. Proc Natl Acad Sci USA 96(25): 14199

Amer HM, Almajhdi FN (2011) Development of a SYBR Green I based real-time RT-PCR assay for detection and quantification of bovine coronavirus. Mol Cell Probes 25(2-3):101-107

Baughman R et al (1999) Science 284(5418): 1340

Belouzard Sandrine, Millet Jean K, Licitra Beth N, Whittaker Gary R (2012) Mechanisms of Coronavirus cell entry mediated by the viral spike protein. Viruses 4(6):1011-1033

Blevins RD (1979) Formulas for natural frequency and mode shape. Van Nostrand Reinhold, New York

Carroll James A, Coleman Sherry A, Smitherman Laura S, Minnick Michael F (2000) Hemin-binding surface protein from Bartonella Quintana. Infect Immun 68(12):6750-6757 
Chen R et al (2003) Proc Natl Acad Sci USA 100(9):4984

Chowdhury R, Adhikari S (2011) Boron nitride nanotubes as zeptogram-scale bionano sensors: theoretical investigations. IEEE Trans Nanotechnol 10:659-667

Chowdhury R, Adhikari S, Mitchell J (2009) Vibrating carbon nanotube based bio-sensors. Phys E Low Dimens Syst Nanostruct 42(2):104-109

Cornell WD, Bally CI, Gould IR, Merz KM Jr, Feguson DM, Spellmeyer DC, Fox T, Caldwell JW, Kollman PA (1995) J Am Chem Soc 117:5179-5197

Davis J et al (1998) The immobilization of proteins in carbon nanotubes. Inorg Chim Acta 272(1-2):261

Davis J et al (2003) Chem Eur J 9(16):3732

Dereli G, Ozdogan C (2003) Structural stability and energetics of single walled carbon nanotubes under uniaxial strain. Phys Rev B 67(3):035416

Dresselhaus MS, Dresselhaus G, Avouris P (eds) (2001) Carbon nanotubes: synthesis, properties and applications. Springer, Berlin

Elishakoff I, Versaci C, Muscolino G (2011) Clamped-free doublewalled carbon nanotube-based mass sensor. Acta Mech 219:29-43

Fennimore A et al (2003) Rotational actuators based on carbon nanotubes. Nature 424(6947):408

Georgantzinos SK, Anifantis NK (2010) Carbon nanotube-based resonant nano mechanical sensors: a computational investigation of their behavior. Physica E 42:1795-1801

Giannopoulos GI, Kakavas PA, Anifantis NK (2008) Evaluation of the effective mechanical properties of single walled carbon nanotubes using a spring based finite element approach. Comput Mater Sci 41:561-569

Gooding J et al (2003) J Am Chem Soc 125(30):9006

Gu L, Elkin T, Jiang X, Li H, Lin Y, Qu L, Tzeng T-RJ, Joseph R, Sun Y-P (2005) Single-walled carbon nanotubes displaying multivalent ligands for capturing pathogens. Chem Commun $7: 874$

Haddon R (2002) Carbon nanotubes. Acc Chem Res 35(12):997

He XQ, Kitipornchai S, Liew KMJ (2005) Mech Phys Solids 53:303

Iijima S (1991) Helical microtubules of graphitic carbon. Nature 354(6348):56

Iijima S, Ichihashi T (1993) Single-shell carbon nanotubes of 1-nm diameter. Nature 363(6430):603

Yoon J, Ru CQ, Mioduchowski A (2003) Vibration of an embedded multiwall carbon nanotube. Compos Sci Technol 63:1533-1542

Jensen K, Kim K, Zettl A (2008) An atomic-resolution nanomechanical mass sensor. Nat Nanotechnol 3:533-537

Joshi AY, Harsha SP, Sharma SC (2010) Vibration response analysis of doubly clamped single walled wavy carbon nanotube based nano mechanical sensors, ASME J Nanotechnol Eng Med 1(3):031004-1-031004-5

Joshi AY, Harsha SP, Sharma SC (2010b) Vibration signature analysis of single walled carbon nanotube based nano mechanical sensors. Phys E Low Dimens Syst Nanostruct 42(8):2115-2123

Kumar O, Singh Y, Rao VK, Vijayaraghavan R (2008) Carbon nanotubes: detection of chemical and biological warfare agents. Defence Sci J 58(5):617

Lee S, Yoon DS (2007) Biochip J 1(3):193

Li C, Chou T-W (2003a) A structural mechanics approach for the analysis of carbon nanotubes. Int J Solids Struct 40:2487-2499

Li C, Chou T-W (2003b) Single-walled carbon nanotubes as ultrahigh frequency nano mechanical resonators. Phys Rev B Condens Matter Mater Phys 68:734051-734053
Li C, Chou T-W (2004a) Vibrational behaviors of multi-walled carbon nanotube based nano mechanical resonators. Appl Phys Lett 84(1):121-123

Li CY, Chou TW (2004b) Mass detection using carbon nanotubebased nanomechanical resonators. Appl Phys Lett 84(25): $5246-5248$

Li J et al (2003) Nano Lett 3(5):597

Lin Y, Taylor S, Li H, Shiral Fernando KA, Qu L, Wang W, Gu L, Zhou B, Sun YP (2004) Advances toward bio applications of carbon nanotubes. J Mater Chem 14(4):527

Lu F et al (2009) Advances in bio applications of carbon nanotubes. Adv Mater 21(2):139

Maguina C, Gotuzzo E (2000) Bartonellosis: new and old. Infect Dis Clin N Am 14(1):1-22. doi:10.1016/S0891-5520(05)70215-4

Mattson M, Haddon R, Rao A (2000) Molecular functionalisation of carbon nanotubes and use as substrates for neuronal growth. J Mol Neurosci 14(3):175

Meirovitch L (1997) Principles and techniques of vibrations. PrenticeHall Inc., New Jersey

Patel AM, Joshi AY (2014a) Investigating the influence of surface deviations in double walled carbon nanotube based nanomechanical sensors. Comput Mater Sci 89:157-164. doi:10.1016/j. commatsci.2014.03.034

Patel Ajay M, Joshi AY (2013) Vibration analysis of double wall carbon nanotube based resonators for zeptogram level mass recognition. Comput Mater Sci 79:230-238

Patel Ajay M, Joshi AY (2014b) Effect of waviness on the dynamic characteristics of double walled carbon nanotubes. Nanosci Nano technol Lett 6:1-9

Rivas GA et al (2007) Carbon nanotubes for electrochemical biosensing. Talanta 74(3):291

Saito R, Matsuo R, Kimura T, Dresselhaus G, Dresselhaus MS (2001) Chem Phys Lett 348:187

Sanchez-Portal D, Artacho E, Soler JM (1999) Ab initio structural, elastic and vibrational properties of carbon nanotubes. Phys Rev B 59(19):12678-12688

Sohlberg K, Sumpter BG, Tuzun RE, Noid DW (1998) Continuum methods of mechanics as a simplified approach to structural engineering of nanostructures. Nanotechnology 9:30

Tsang SC, Davis JJ, Green MLH, Allen H, Hill O, Leung YC, Sadler PJ (1995) Immobilization of small proteins in carbon nanotubes: high-resolution transmission electron microscopy study and catalytic activity. J Chem Soc Chem Commun 17:1803

Tserpes KI, Papanikos P (2005) Finite element modeling of singlewalled carbon nanotubes. Compos B 36:468-477

Wang J (2005) Carbon-nanotube based electrochemical biosensors: a review. Electroanalysis 17(1):7

Wong S et al (1998) Covalently functionalized nanotubes as nanometer-sized probes in chemistry and biology. Nature 394(6688):52

Wu W, Palaniapan M, Wong W-K (2008) Multiwall carbon nanotube resonator for ultra-sensitive mass detection. Electron Lett 44(18):1932-1933

Xu KY, Aifantis EC, Yan YH (2008) Vibrations of double-walled carbon nanotubes with different boundary conditions between inner and outer tubes. J Appl Mech 75(2):021013

Yang Y, Callegari C, Feng X, Ekinci K, Roukes M (2006) Zeptogram scale nanomechanical mass sensing. Nano Lett 6(4):583-586

Yun Y et al (2007) Nanotube electrodes and biosensors. Nano Today $2(6): 30$ 